\title{
Diretrizes para a definição de lotes de montagem de sistemas pré-fabricados de concreto do tipo engineer-to-order
}

\author{
Guidelines for defining assembly batches of engineer-to- \\ order concrete prefabricated systems
}

\section{Raquel Hoffmann Reck \\ Fernanda Saidelles Bataglin \\ Carlos Torres Formoso \\ Karina Bertotto Barth \\ Thomas Diepenbruck \\ Eduardo Luis Isatto}

${ }^{1}$ Raquel Hoffmann Reck ${ }^{1}$ Universidade Federal do Rio Grande do Sul Porto Alegre - RS - Brasil

${ }^{2}$ Fernanda Saidelles Bataglin ${ }^{2}$ Universidade Federal do Rio Grande do Sul Porto Alegre - RS - Brasil

${ }^{3}$ Carlos Torres Formoso ${ }^{3}$ Universidade Federal do Rio Grande do Sul Porto Alegre - RS - Brasil

${ }^{4}$ Karina Bertotto Barth ${ }^{4}$ Universidade Federal do Rio Grande do Sul

Porto Alegre - RS - Brasil

${ }^{5}$ Thomas Diepenbruck 5HTB Engenharia e Construção S. A. São Paulo - SP - Brasil

${ }^{6}$ Eduardo Luis Isatto ${ }^{6}$ Universidade Federal do Rio Grande Porto Alegre - RS - Brasil

Recebido em 26/03/19 Aceito em 15/08/19

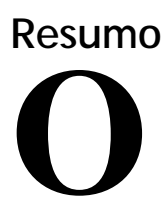

s potenciais benefícios do uso de sistemas construtivos pré-fabricados do tipo engineer-to-order (ETO) abrangem desde a redução de custos e duração do empreendimento até melhorias na qualidade do produto. Entretanto, o escopo de sistemas de planejamento e controle da produção neste contexto deve ser diferente de empreendimentos tradicionais, pois existe a necessidade de coordenar diferentes tipos de fluxos (projeto, fabricação, operações logísticas e montagem). Neste contexto, é necessária a estabilização desses fluxos e consequente diminuição do trabalho em progresso, o que é relacionado ao esforço de reduzir o tamanho do lote de produção. O objetivo do presente trabalho é propor um conjunto de diretrizes para a definição dos lotes de montagem para sistemas pré-fabricados de concreto do tipo ETO com apoio de BIM 4D, com base em conceitos e princípios da produção enxuta. Design Science Research foi a abordagem metodológica adotada, tendo como base um estudo empírico em uma obra de ampliação de um aeroporto. As principais contribuições do trabalho são um conjunto de categorias de decisão para a definição dos lotes de montagem, e o desenvolvimento de ferramentas para apoiar a tomada de decisões.

Palavras-chave: Engineer-to-order. Sistemas pré-fabricado em concreto. Produção enxuta. BIM 4D. Linha de balanço.

\section{Abstract}

The potential benefits of engineer-to-order (ETO) prefabricated building systems include reductions in project cost and duration, and improvements in product quality. However, the scope of production planning and control systems in that context must be different from traditional projects, since it is necessary to coordinate different types of flows (design, manufacturing, logistics operations and site assembly). In this context, it is necessary to stabilise those flows and consequently reduce work in progress, which is strongly related to the effort of reducing production batch size. The aim of this research work is to propose a set of guidelines for the definition of assembly batches for ETO prefabricated concrete system, with the support of 4D BIM, based on concepts and principles of the lean production philosophy. Design Science Research was the methodological approach adopted in this investigation, which was based on an empirical study carried out in an airport expansion project. The main contributions of this study are a set of decision categories for the definition of assembly batches, and the development of tools for supporting decision-making in this context.

Keywords: Engineer-to-order. Prefabricated concrete systems. Lean Production. 4D BIM. Line of balance. 


\section{Introdução}

Uma elevada parcela das empresas de construção industrializada fornece sistemas de produção do tipo Engineer-to-order (ETO) em função da necessidade de rápidas respostas às demandas dos clientes (MCGOVERN; HICKS; EARL, 1999; PHENG; CHUAN, 2001; MELLO; STRANDHAGEN; ALFNES, 2015). Os sistemas de produção ETO podem ser definidos como aqueles em que o ponto de desacoplamento do pedido do cliente (customer order decoupling point - CODP) está localizado na etapa de projeto do produto (GOSLING; NAIM, 2009), sendo que o pedido do cliente é um produto único que atende às necessidades específicas do mesmo (BERTRAND; MUNTSLAG, 1993).

Por um lado, a introdução da construção industrializada permite realizar algumas etapas da produção em um ambiente controlado, evitando condições imprevisíveis nos canteiros de obras (LESSING; STEHN; EKHOLM, 2005). Por outro lado, com a adoção de sistemas pré-fabricados ETO, o processo de construção tende a tornar-se mais complexo e vulnerável a partir da necessidade de dois locais de produção: fábrica e canteiro de obras (KOSKELA, 1992). Neste contexto, o esforço de coordenação passa a ser especialmente importante, visto que muitas empresas fornecedoras desse sistema atendem a múltiplos empreendimentos

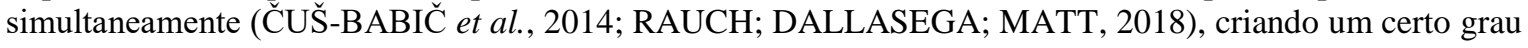
de interdependência entre estes.

A interpendência entre a montagem no canteiro de obras e a produção na fábrica é particularmente importante em sistemas ETO. Se por um lado, os atrasos na entrega dos componentes podem gerar custos adicionais devido à mão de obra e equipamentos parados, por outro, a produção e entrega antecipadas tendem a gerar estoques excessivos, aumentando o esforço despendido com a movimentação de componentes em obra (Č́UŠBABIČ et al., 2014). Ou seja, para gerenciar o fluxo de produtos são necessárias informações precisas, confiáveis e atualizadas sobre o status do sistema de produção (EASTMAN et al., 2011).

Assim, o escopo do planejamento e controle em sistemas ETO tende a ser diferente de obras tradicionais, pois desempenham o importante papel de coordenar diferentes tipos de fluxos (projeto, fabricação, operações logísticas e montagem no canteiro de obras) em um ambiente com um alto nível de incerteza (VIANA, 2015). A realização das atividades planejadas depende da confiabilidade destes fluxos, ou seja, deve-se garantir que os recursos adequados estejam disponíveis no momento certo (THOMAS et al., 2002). De fato, uma das principais causas de perdas nos canteiros de obra é a interrupção de fluxos de trabalho, que é usualmente resultado da alta variabilidade do sistema de produção e pela falta de sincronização entre os processos (BULHÕES; PICCHI; FOLCH, 2006).

No presente trabalho, discute-se o uso combinado dos conceitos e princípios da produção enxuta (Lean Production) e das funcionalidades do Building Information Modeling (BIM) para apoiar a gestão da produção em sistemas pré-fabricados do tipo ETO, visto que existe sinergia entre ambas as abordagens (SACKS et al., 2010). A produção enxuta, originária da indústria automotiva, tem sido amplamente disseminada na indústria da construção, sendo que um de seus objetivos é alcançar a estabilidade dos fluxos de produção, contribuindo para melhorias nos processos de construção (SACKS et al., 2010). Por sua vez, BIM pode ser definido como uma abordagem orientada pela tecnologia da informação (PAPADONIKOLAKI; VRIJHOEF; WAMELINK, 2015) que tem como característica principal facilitar o compartilhamento e o reuso das informações durante todo o ciclo de vida do empreendimento (LEE; YU; JEONG, 2013). Dessa forma, BIM fornece uma plataforma para a visualização do fluxo de trabalho em sistemas de controle, facilitando a introdução de processos colaborativos entre as equipes de trabalho dentro e fora do canteiro (SACKS; RADOSAVLJEVIC; BARAK, 2010). De fato, BIM 4D tem sido crescentemente utilizado para apoiar a tomada de decisão na gestão da produção (CHOI et al., 2014; KASSEM; DAWOOD; CHAVADA, 2015; YU; LI; LUO, 2016; BORTOLINI; FORMOSO; VIANA, 2019). Biotto, Formoso e Isatto (2015) sugerem que a modelagem 4D deve ser utilizada de forma complementar a ferramentas de planejamento, como, por exemplo, a linha de balanço (LOB), que permitem a definição e visualização dos ritmos de produção, divisão da obra em lotes, e fluxos de trabalho.

Alguns conceitos e princípios da Lean Construction têm um importante papel de conexão entre a fábrica e a obra no contexto de sistemas ETO (BORTOLINI; FORMOSO; VIANA, 2019). Busca-se evitar paradas no canteiro de obras por falta de componentes e, ao mesmo tempo, reduzir o nível de trabalho em progresso (SKJELBRED; FOSSHEIM; DREVLAND, 2015). A redução do trabalho em progresso está intimamente ligada com o esforço de reduzir o tamanho do lote de produção, que contribui diretamente na redução do tempo de ciclo (HOPP; SPEARMAN, 2004). Como resultados da definição de pequenos lotes de produção, tem-se curtos ciclos de retroalimentação que permitem uma identificação mais rápida dos problemas, o que facilita a implementação de melhorias (BALLARD; HARPER; ZABELLE, 2003). A definição dos lotes de 
produção de uma estrutura pré-fabricada é uma decisão que faz parte do Projeto do Sistema de Produção (PSP) de um empreendimento de construção, e deve ser tomada antes do início da etapa de execução da obra (SCHRAMM; FORMOSO, 2015).

Em que pese o fato de que pesquisas anteriores sobre o PSP abordaram a definição de lotes de produção (SCHRAMM; FORMOSO, 2015), alguns com o uso de BIM para apoiar este processo (BIOTTO, FORMOSO; ISATTO, 2015; BATAGLIN et al. 2018; BORTOLINI; FORMOSO; VIANA, 2019), nenhuma delas realizou uma análise aprofundada e sistemática dos critérios a serem seguidos para definir lotes de produção para sistemas ETO. Assim, o presente artigo propõe diretrizes para a definição dos lotes de montagem para sistemas pré-fabricados de concreto do tipo ETO com o apoio das ferramentas BIM 4D, com base em conceitos e princípios da produção enxuta. Este estudo foi desenvolvido em colaboração com um consórcio de empresas construtoras envolvido na ampliação de um aeroporto, que estava em pleno funcionamento no período da obra. A obra estudada foi a execução de uma estrutura pré-fabricada em concreto referente a um edifício-garagem. O ponto de partida do presente trabalho foi a demanda do consórcio de empresas de explorar o uso da modelagem BIM 4D para apoiar o planejamento e controle desta obra.

\section{Projeto do Sistema de Produção (PSP) e definição dos lotes de produção}

O PSP pode ser definido como um processo de formulação e análise de diferentes alternativas de estruturação e organização dos processos que constituem o sistema de produção do empreendimento, sendo necessário negociar as principais interdependências e necessidades de fornecedores e subcontratados (SCHRAMM; FORMOSO, 2015). Existem diversas categorias de decisão envolvidas no PSP, tais como o sequenciamento de processos, a definição de ritmos e fluxos das equipes, o dimensionamento de equipamentos e da mão de obra, a definição do leiaute, a inclusão de buffers e o tamanho dos lotes (SCHRAMM; FORMOSO, 2005; VIANA, 2015).

Schramm e Formoso (2015) propuseram um modelo para elaboração de PSP para empreendimentos habitacionais de interesse social, que se baseia na definição dos lotes de produção, para depois elaborar o plano para o empreendimento como um todo. Neste modelo são analisados primeiramente o sequenciamento, prédimensionamento de recursos e análise de fluxos da unidade base (ou seja, a unidade repetitiva). Em seguida, são definidos e analisados os ritmos de produção, o dimensionamento de recursos e os principais fluxos do trabalho.

Os mesmos autores sugerem o uso da LOB para a representação dos principais fluxos de trabalho. Esta técnica de planejamento e controle tem como foco a definição do ritmo de produção e o balanceamento das operações, de forma que cada atividade seja continuamente executada, tendo um formato gráfico de fácil interpretação (ARDITI; TOKDEMIR; SUH, 2002; LOWE et al., 2012). Na LOB o empreendimento é dividido em seções físicas, ou lotes, e busca-se estabelecer um ritmo da produção, a partir do qual são sincronizados diferentes processos (JONGELING; OLOFSSON, 2007). Para que isto ocorra, é necessário que as equipes sejam dimensionadas para que os processos tenham ritmos semelhantes, podendo ser reduzidas as folgas de tempo (KANKAINEN; SEPPÄNEN, 2003).

Bulhões (2009) sugere que as obras de estruturas de concreto pré-fabricadas devem ser segmentadas em módulos, de forma a definir lotes relativamente pequenos que podem ter um certo grau de repetição. Com a redução do tamanho do lote de montagem, o processo de montagem na obra pode puxar a fabricação e a entrega de componentes na obra, de maneira a manter um baixo nível de trabalho em progresso, bem como considerar a variabilidade da demanda que tipicamente existe no canteiro de obras (BULHÕES; PICCHI; FOLCH, 2006; BATAGLIN et al., 2018; BORTOLINI; FORMOSO; VIANA, 2019). Entretanto, a existência de incertezas no canteiro de obras, seja por indefinições no projeto ou mudanças no sequenciamento de atividades predecessoras, faz com que haja a necessidade de definição de pontos de confirmação na produção das peças na fábrica e também na entrega dos componentes na obra (VIANA, 2015; BATAGLIN et al., 2018). Neste contexto, pode ser aplicada a definição ampla de produção puxada, proposta por Hopp e Spearman (2004): a liberação do trabalho é feita de acordo com o status do sistema, ao invés de ser baseado no pedido do cliente final.

Assim, existe a necessidade de realizar um cuidadoso processo de tomada de decisão para definir o conteúdo do lote a ser adotado, diferentemente de algumas tipologias de obras de edificações, nas quais existe uma unidade repetitiva naturalmente definida (por exemplo, um apartamento, uma casa, um pavimento). Os lotes devem ser definidos considerando a capacidade das equipes de montagem, de produção da fábrica e da 
logística de entrega dos componentes, com base em planos de carga, sendo que tais definições têm um importante papel no controle do fluxo de componentes (BATAGLIN et al., 2018). Neste contexto, BIM 4D pode ser utilizado para apoiar a tomada de decisão, visando a reduzir a incerteza dos processos no canteiro de obras, limitar o trabalho em progresso e liberar o trabalho com base em informações sobre o status da produção. Este uso será discutido a seguir.

\section{BIM na gestão de sistemas pré-fabricados ETO}

Schlueter e Thesseling (2009) afirmam que os modelos BIM são repositórios capazes de armazenar tanto informações geométricas como informações semânticas, que descrevem as propriedades dos componentes e informações topológicas que captam dependências entre estes. Segundo Eastman et al. (2011), ao representar uma construção por objetos inteligentes que carregam informações detalhadas sobre si mesmos e também entendem seu relacionamento com outros objetos do modelo, o BIM não só altera a forma como os desenhos de construção e visualizações são criados, mas também altera outros processos-chave envolvidos na gestão da construção, sendo um deles o planejamento e controle da produção. A adoção do BIM pode melhorar potencialmente a qualidade das informações disponíveis para o planejamento e controle, podendo contribuir para aumentar a previsibilidade da entrega do empreendimento (GLEDSON; GREENWOOD, 2017).

Especificamente com relação ao uso do BIM 4D, a visualização dos processos de construção permite que os envolvidos no empreendimento entendam mais facilmente as restrições espaciais e explorem alternativas de execução antes do início da obra (FARD et al., 2009; ZHANG et al., 2016). Os modelos 4D são também úteis no planejamento do uso dos espaços, que representam um recurso muitas vezes limitado no canteiro de obras (CHAVADA; DAWOOD; KASSEM, 2012), resultando em melhorias no leiaute do canteiro de obras (ZHANG; LI, 2010).

De acordo com Said e El-Rayes (2012), planejar a logística dos materiais em canteiros de obras é uma tarefa desafiadora devido à escassez de espaço para acomodar áreas de armazenamento de materiais em função de atividades de construção e instalações provisórias. Yu, Li e Luo (2016) desenvolveram um modelo dinâmico baseado em BIM para o fornecimento de materiais com o objetivo de fazer com que os materiais necessários possam sejam fornecidos para as equipes de construção nas quantidades, datas e locais corretos. Com o propósito de evitar retrabalhos e perdas na produtividade das equipes, Choi et al. (2014) sugeriram uma estrutura para o processo de planejamento do espaço de trabalho em um ambiente BIM 4D integrado ao planejamento da construção. No mesmo sentido, Bortolini, Formoso e Viana (2019) propuseram um modelo hierarquizado para gerenciar a logística interna de canteiros de obras no âmbito sistemas pré-fabricados ETO utilizando modelos 4D, incluindo tarefas como:

(a) definição da sequência montagem;

(b) definição do leiaute do canteiro de obra, com alocação das instalações provisórias, equipamentos, áreas de armazenamento e rotas de acesso;

(c) análise dos conflitos entre planos de diferentes equipes de trabalho no canteiro;

(d) projeto das operações de carga e descarga; e

(e) análise de processos críticos de montagem.

\section{Método de pesquisa}

\section{Abordagem metodológica}

A pesquisa está posicionada como Design Science Research (DSR), que é um modo de produção de conhecimento científico de caráter prescritivo, no qual se desenvolve construções inovadoras (ou artefatos), projetadas para resolver classes de problemas encontrados no mundo real e, ao mesmo tempo, fazer contribuições teóricas (LUKKA, 2003). O artefato proposto no presente estudo é um conjunto de diretrizes para a definição dos lotes de produção para sistemas pré-fabricados de concreto do tipo ETO com o uso de BIM 4D, com base em conceitos e princípios da produção enxuta. Neste tipo de estudo, o ponto de partida para a realização da pesquisa é o conhecimento profundo de uma classe de problemas práticos (VAN AKEN, 2004), neste caso a necessidade de definir lotes de montagem em sistemas pré-fabricados de concreto, visando a permitir que a fabricação e a entrega dos mesmos sejam puxadas.

Nesta pesquisa foram realizados ciclos de aprendizagem, abrangendo as etapas de compreensão do problema e do contexto, planejamento da intervenção, realização da intervenção e avaliação dos resultados, conforme 
sugerido por Van Aken (2004). Estes ciclos permitiram uma estreita colaboração entre os pesquisadores e representantes das empresas, sendo que o conjunto de diretrizes emergiu ao longo deste estudo empírico. Dessa forma, a estratégia de pesquisa adotada foi similar à pesquisa-ação, mas posicionada como DSR, conforme sugerido por Järvinen (2007).

\section{Descrição das empresas e do empreendimento estudado}

O estudo realizado em parceria com o consórcio de empresas (denominado neste artigo como empresa construtora) envolveu a realização do planejamento logístico da estrutura pré-fabricada do edifício garagem. Esta obra foi escolhida por utilizar sistema ETO e também porque uma das empresas do consórcio possuía um programa de implementação de melhorias com base em conceitos e princípios da produção enxuta. Também participou deste estudo a empresa que projetou, fabricou e montou a estrutura pré-fabricada, denominada neste artigo de empresa fornecedora. A mesma possui quatro fábricas em operação e tem grande experiência na entrega de estruturas ETO. A empresa fornecedora foi contratada ao longo do estudo, não participando das etapas iniciais.

A Figura 1a representa a planta baixa da edificação, enquanto a Figura 1b mostra o modelo BIM 3D. A obra tinha aproximadamente $6.000 \mathrm{~m}^{2}$ de área construída, dividida em 5 pavimentos, apresentando o formato quadrado com 11 eixos numa direção (1 ao 11) e 11 eixos na outra direção (A a K). Os pilares consistiam em peças únicas ao longo dos 5 níveis da estrutura, sendo as vigas, lajes e painéis de fachada seccionados nas interseções de cada eixo. A execução da obra foi planejada e orçada pela empresa construtora por níveis, sem uma definição de lotes para sincronizar fabricação, transporte e montagem das peças pré-fabricadas em concreto. O prazo inicial para execução da montagem era de quatro meses.

\section{Delineamento da pesquisa}

O estudo foi dividido em três etapas:

(a) compreensão;

(b) desenvolvimento; e

(c) análise e reflexão.

A etapa de compreensão consistiu na análise aprofundada do problema real, considerando o sistema de planejamento utilizado inicialmente pela empresa construtora.

Na etapa de desenvolvimento foi realizado o planejamento logístico da obra com o objetivo de tornar puxada a fabricação e o transporte das peças pelo processo de montagem. Para isso, utilizou-se a linha de balanço, BIM 4D e algumas ferramentas auxiliares para criar diferentes cenários. Estes cenários foram propostos para dar suporte à tomada de decisão tanto para a empresa construtora como para a empresa fornecedora.

A elaboração dos cenários teve início dois meses antes do início e o último um mês antes do final da montagem. Todos os cenários foram elaborados pelos autores deste trabalho, sendo apresentados em reuniões de planejamento, primeiramente de concepção do sistema de produção e depois de planejamento e controle nos níveis de médio e curto prazo. Em muitas destas reuniões, as empresas participantes solicitavam a simulação de novos cenários.

\section{Figura 1 - Empreendimento estudado}

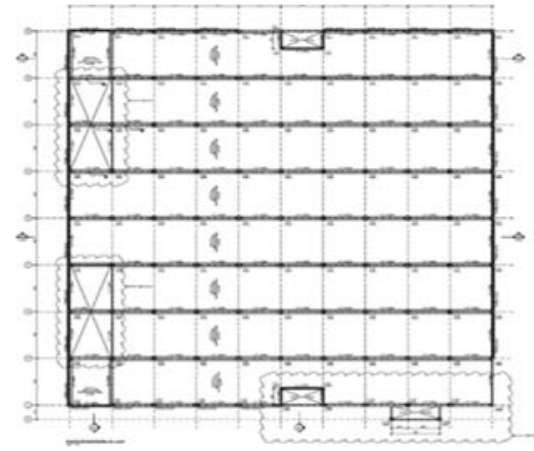

(a) Planta baixa

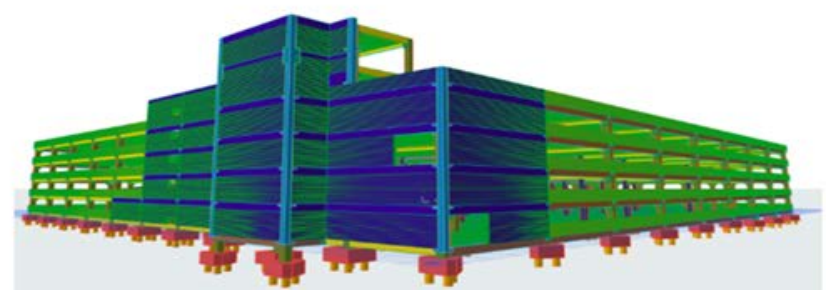

(b) Modelo BIM 3D em perspectiva

Fonte: empresa construtora. 
O Quadro 1 apresenta uma breve descrição das 11 simulações realizadas, na qual são apresentados o número de lotes, o número de guindastes, tipo de modelo BIM e programa no qual foi modelado, e a técnica de planejamento empregada.

Os cenários podem ser divididos em três etapas de acordo com o objetivo das simulações. O número de cenários por etapa variou de acordo com a necessidade e compreensão dos resultados por parte da equipe de pesquisa e das empresas participantes. No item de resultados apenas os cenários mais relevantes são apresentados. A seguir são apresentadas as etapas de simulações:

(a) definição do lote pela empresa construtora: nesta etapa foram simulados sete cenários, iniciando pelo cronograma inicial elaborado pela empresa construtora e passando pela aplicação dos conceitos de fluxo ininterrupto e trabalho padronizado. Nesta etapa apenas o grupo de pesquisa e representantes da empresa construtora analisaram os resultados das simulações;

(b) definição do lote pela empresa fornecedora: nesta etapa foram simulados dois cenários, considerando requisitos de segurança e logística da empresa fornecedora, após a mesma ter sido contratada; e

(c) acompanhamento da execução: nesta etapa foram simulados três cenários, concomitantemente à execução da obra, com o objetivo de avaliar alternativas, caso fossem necessárias, para redução de prazo.

A última etapa de trabalho consistiu na definição dos constructos e na avaliação do artefato, visando analisar criticamente as contribuições do trabalho. Esta avaliação foi realizada por meio dos constructos de aplicabilidade e utilidade (Quadro 2), sugeridos por Bataglin (2017).

\section{Quadro 1 - Simulações realizadas}

\begin{tabular}{|c|c|c|c|c|c|c|}
\hline Simulações & Lotes & Sequência & $\begin{array}{c}\mathbf{N}^{\mathbf{0}} \\
\text { guindastes }\end{array}$ & $\begin{array}{l}\text { Modelo - } \\
\text { Programa }\end{array}$ & $\begin{array}{c}\text { Técnica de } \\
\text { planejamento }\end{array}$ & Etapa do estudo \\
\hline $\begin{array}{c}\text { Cronograma } \\
\text { inicial }\end{array}$ & $\begin{array}{c}\text { por } \\
\text { nível }\end{array}$ & - & - & \multirow{3}{*}{$\begin{array}{c}\text { Arquitetônico - } \\
\text { ArchiCAD* }\end{array}$} & CPM/LOB & \multirow{7}{*}{$\begin{array}{l}\text { definição do lote } \\
\text { pela construtora }\end{array}$} \\
\hline Cenário 1 & por eixo & 1 & - & & CPM & \\
\hline Cenário 2 & por eixo & 2 & - & & CPM & \\
\hline Cenário 3 & 22 & 3 & 1 & \multirow{4}{*}{$\begin{array}{c}\text { Arquitetônico - } \\
\text { Revit }\end{array}$} & LOB & \\
\hline Cenário 4 & 22 & 4 & 2 & & LOB & \\
\hline Cenário 5 & 22 & 5 & 2 & & LOB & \\
\hline Cenário 6 & 22 & 4 & 2 & & LOB & \\
\hline Cenário 7 & 15 & 6 & 2 & \multirow{2}{*}{$\begin{array}{c}\text { Estrutural } 1^{\mathrm{a}} \\
\text { versão - Tekla }\end{array}$} & LOB & \multirow{2}{*}{$\begin{array}{c}\text { definição do lote } \\
\text { pela empresa } \\
\text { fornecedora }\end{array}$} \\
\hline Cenário 8 & 17 & 7 & 2 & & LOB & \\
\hline Cenário 9 & 17 & 7 & 2 & \multirow{2}{*}{ 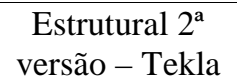 } & LOB & \multirow{3}{*}{$\begin{array}{c}\text { acompanhamento } \\
\text { da execução }\end{array}$} \\
\hline Cenário 10 & 17 & 8 & 3 & & LOB & \\
\hline Cenário 11 & 17 & 9 & 2 & $\begin{array}{c}\text { Estrutural } 3^{\mathrm{a}} \\
\text { versão - Tekla }\end{array}$ & LOB & \\
\hline
\end{tabular}

Nota: *este primeiro modelo foi realizado pelo grupo de pesquisa no ArchiCAD a partir de plantas em 2D do arquitetônico disponibilizado pela empresa construtora.

\section{Quadro 2 - Constructos para avaliação do artefato}

\begin{tabular}{|c|c|c|}
\hline Constructo & Subconstructos & Fonte de evidência \\
\hline \multirow{4}{*}{ Aplicabilidade } & Tempo gasto na preparação de modelos e simulações & $\begin{array}{c}\text { Tempo de preparação } \\
\text { para as reuniões }\end{array}$ \\
\cline { 2 - 3 } & $\begin{array}{c}\text { Compreensão por parte dos intervenientes das } \\
\text { ferramentas e conceitos fundamentais }\end{array}$ & Observação participante \\
\hline \multirow{3}{*}{ Utilidade } & $\begin{array}{c}\text { Introdução de um conjunto de conceitos Lean no } \\
\text { processo de tomada de decisão }\end{array}$ & Observação participante \\
\cline { 2 - 3 } & $\begin{array}{c}\text { Contribuição para a definição de um ciclo de } \\
\text { produção curto e com certo grau de repetição }\end{array}$ & $\begin{array}{c}\text { Análise de documentos e } \\
\text { observação participante }\end{array}$ \\
\cline { 2 - 3 } & Geração de alternativas de planos para apoiar a \\
tomada de decisão & $\mathrm{N}^{\circ}$ de cenários simulados \\
\cline { 2 - 3 } & Complementaridade entre as ferramentas propostas & Observação participante \\
\hline
\end{tabular}




\section{Métodos e técnicas de coletas de dados}

No Quadro 3 são apresentadas as fontes de evidências utilizadas em cada etapa, bem como os objetivos para as ações desenvolvidas ao longo do estudo.

\section{Quadro 3 - Fontes de evidência por etapas do estudo}

\begin{tabular}{|c|c|c|c|}
\hline \multicolumn{2}{|r|}{ Ação } & $\begin{array}{l}\text { Fontes de } \\
\text { Evidência }\end{array}$ & Descrição \\
\hline \multirow{5}{*}{ 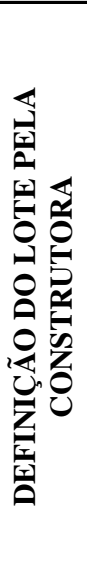 } & \multirow{3}{*}{$\begin{array}{l}\text { Preparação } \\
\text { para as } \\
\text { reuniões }\end{array}$} & \multirow{2}{*}{$\begin{array}{l}\text { Modelo } \\
\text { Digital }\end{array}$} & 1 modelo volumétrico desenvolvido no Archicad - 8h de modelagem \\
\hline & & & $\begin{array}{l}6 \text { modelos BIM 4D - 8h de modelagem em média por cenário, } \\
\text { desenvolvido no Synchro } 2018\end{array}$ \\
\hline & & $\begin{array}{l}\text { Análise de } \\
\text { documentos }\end{array}$ & 7 linhas de balanço desenvolvida no Excel \\
\hline & $\begin{array}{l}\text { Reuniões de } \\
\text { Planejamento }\end{array}$ & $\begin{array}{l}\text { Observação } \\
\text { participante }\end{array}$ & $\begin{array}{l}8 \text { reuniões - 2h cada - total de } 16 \mathrm{~h} \\
\text { Participantes da empresa construtora: três integrantes do setor de } \\
\text { inovação, o engenheiro de planejamento, o gerente geral de obras, o } \\
\text { engenheiro responsável pela execução, o responsável pelo setor de } \\
\text { suprimentos e o responsável pelo setor de projetos. } \\
\text { Objetivo: coletar premissas de produção da empresa construtora, } \\
\text { apresentar e discutir os cenários simulados nesta etapa, definir o plano } \\
\text { de montagem da obra antes da contratação da empresa fornecedora. }\end{array}$ \\
\hline & $\begin{array}{l}\text { Análise de } \\
\text { documentos }\end{array}$ & $\begin{array}{l}\text { Análise de } \\
\text { dados } \\
\text { secundários }\end{array}$ & Projetos e procedimentos da empresa \\
\hline & Preparação & $\begin{array}{l}\text { Modelo } \\
\text { Digital }\end{array}$ & $\begin{array}{l}2 \text { modelos BIM 4D - 10h de modelagem em média por cenário, } \\
\text { desenvolvido no Synchro } 2018\end{array}$ \\
\hline 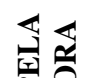 & $\begin{array}{l}\text { para as } \\
\text { reuniões }\end{array}$ & $\begin{array}{l}\text { Análise de } \\
\text { documentos }\end{array}$ & 2 linhas de balanço desenvolvida no Excel \\
\hline 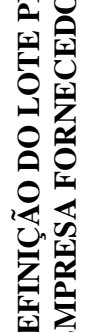 & $\begin{array}{l}\text { Reuniões de } \\
\text { Planejamento }\end{array}$ & $\begin{array}{l}\text { Observação } \\
\text { participante }\end{array}$ & $\begin{array}{l}6 \text { reuniões - } 2 \mathrm{~h} \text { cada - total de } 12 \mathrm{~h} \\
\text { Participantes da empresa construtora: idem à etapa anterior } \\
\text { Participantes da empresa fornecedora: técnico de segurança, } \\
\text { projetista estrutural, consultor de segurança e coordenador de obras } \\
\text { responsável pela execução. } \\
\text { Objetivo: coletar premissas de produção da empresa fornecedora, } \\
\text { apresentar e discutir os cenários simulados nesta etapa, definir o plano } \\
\text { de montagem da obra em conjunto com as empresas fornecedora e } \\
\text { construtora. }\end{array}$ \\
\hline & $\begin{array}{l}\text { Análise de } \\
\text { documentos }\end{array}$ & $\begin{array}{c}\text { Análise de } \\
\text { dados } \\
\text { secundários }\end{array}$ & $\begin{array}{l}\text { Planos de rigging }{ }^{1} \text {, situação do pedido em fábrica, romaneio, } \\
\text { relatórios de expedição e procedimentos de montagem. }\end{array}$ \\
\hline & Preparação & $\begin{array}{c}\text { Modelo } \\
\text { Digital } \\
\end{array}$ & $\begin{array}{l}3 \text { modelos BIM 4D - 8h de modelagem em média por cenário, } \\
\text { desenvolvido no Synchro } 2018\end{array}$ \\
\hline ن্ & $\begin{array}{l}\text { para as } \\
\text { reuniões }\end{array}$ & $\begin{array}{c}\text { Análise de } \\
\text { documentos }\end{array}$ & 3 linhas de balanço desenvolvida no Excel \\
\hline 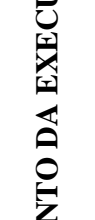 & $\begin{array}{l}\text { Reuniões de } \\
\text { Planejamento }\end{array}$ & $\begin{array}{l}\text { Observação } \\
\text { participante }\end{array}$ & $\begin{array}{l}15 \text { reuniões - 2h cada - total de 30h } \\
\text { Participantes da empresa construtora: idem à etapa anterior } \\
\text { Participantes da empresa fornecedora: idem à etapa anterior } \\
\text { Objetivo: acompanhar os indicadores de montagem em obra, } \\
\text { apresentar e discutir os cenários simulados nesta etapa e realização de } \\
\text { reunião de análise de restrições. }\end{array}$ \\
\hline 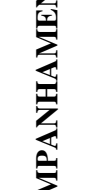 & $\begin{array}{l}\text { Visita ao } \\
\text { canteiro de } \\
\quad \text { obra }\end{array}$ & $\begin{array}{l}\text { Observação } \\
\text { Direta e } \\
\text { Registro } \\
\text { Fotográfico }\end{array}$ & $\begin{array}{l}21 \text { observações diretas em campo - 2h30min em média - 51h40min de } \\
\text { observação } \\
\text { Objetivo: identificação de estoques em canteiro, análise dos fluxos de } \\
\text { trabalho e coleta de tempos das atividades de operações dos } \\
\text { guindastes. }\end{array}$ \\
\hline 方 & $\begin{array}{l}\text { Análise de } \\
\text { documentos }\end{array}$ & $\begin{array}{l}\text { Análise de } \\
\text { dados } \\
\text { secundários }\end{array}$ & $\begin{array}{l}\text { Relatórios de qualidade e atas de reunião da produção contendo a } \\
\text { análise de restrições realizada pela empresa construtora, relatórios de } \\
\text { diário de obra e controle de peças montadas elaborado pela empresa } \\
\text { fornecedora. }\end{array}$ \\
\hline
\end{tabular}

1Plano de rigging é o plano de movimentação de carga, que consiste no planejamento formalizado de uma movimentação com guindaste móvel ou fixo, visando à otimização dos recursos aplicados na operação para se evitar acidentes e perdas de tempo. 


\section{Resultados}

\section{Desenvolvimento da pesquisa}

\section{Definição do lote pela empresa construtora}

Inicialmente, foi analisado o padrão de repetição considerado no plano de longo prazo da obra e as interferências das outras atividades na montagem das peças. Para isso, o plano de longo prazo inicial, elaborado como uma rede CPM foi traduzido para uma LOB, conforme apresentado na Figura 2. Inicialmente foi criado na LOB um sistema de localização para visualizar os principais processos: estrutura de concreto pré-moldado (cotas 0,0 m; 3,2 m; 6,4 m; 9,6 m; 12,8 m), paredes de alvenaria, acabamentos internos e externos. O processo de montagem foi subdividido conforme as diferentes peças (pilares, vigas, lajes e fechamento). Para as atividades de estrutura, foi possível identificar repetições por nível. No entanto, para as demais, como alvenaria e acabamentos, não foi possível identificar qualquer repetição, sendo estas representadas como atividades únicas. Com esta análise foi possível identificar alguns problemas:

(a) falta de definição de lotes para a realização das atividades;

(b) falta de definição de um plano de ataque; e

(c) falta de planejamento dos fluxos físicos no canteiro, principalmente com relação ao posicionamento dos guindastes e locais de armazenamento de peças.

Após a análise do plano inicial, foi definida a primeira proposta de divisão em lotes. Para isso, foi necessário definir o sequenciamento de montagem das peças dentro de um lote e estimar a produtividade de montagem de peças por dia. Considerou-se o índice de produtividade adotado pela empresa construtora, que permitiria a montagem de 8 pilares e um conjunto de 30 peças entre vigas, lajes e painéis de fachada, por dia, por equipamento. Com base nestas informações, foram simuladas algumas configurações de lotes de produção e quantificado o número e tipo de peças por lote. Como o número de peças por lote utilizado deveria ser similar para cada ciclo de produção, foi definido um tempo de ciclo de 5 dias por lote, para atender a montagem dos lotes com o maior número de peças.

Para a definição do tamanho dos lotes, foi criada a planilha de mapeamento de peças por eixo, a qual tem o objetivo de quantificar o número de peças pelo tipo e pelo lote. Esta planilha calculava automaticamente o número de peças (Figura 3a) a partir da inserção das letras dos lotes na representação espacial em planta baixa dos eixos (Figura $3 b$ ). Para tanto, foi necessário realizar um mapeamento do número de peças de acordo com os eixos e tipo (Figura 3c e Figura 3d). Conforme indica a Figura 3c, os pilares são quantificados exatamente na interseção dos eixos na cor azul, as vigas no vão entre os eixos na cor verde, os painéis de fachada no centro do quadrante na parte superior na cor azul claro e as lajes no centro do quadrante na parte inferior na cor amarela. As Figura 3c e Figura 3d apresentam o mapeamento de um único nível. Na contagem final das peças (Figura 3b) era realizada a multiplicação pelo número de níveis para cada tipo de peça.

\section{Figura 2 - LOB gerada a partir do plano de longo prazo inicial}

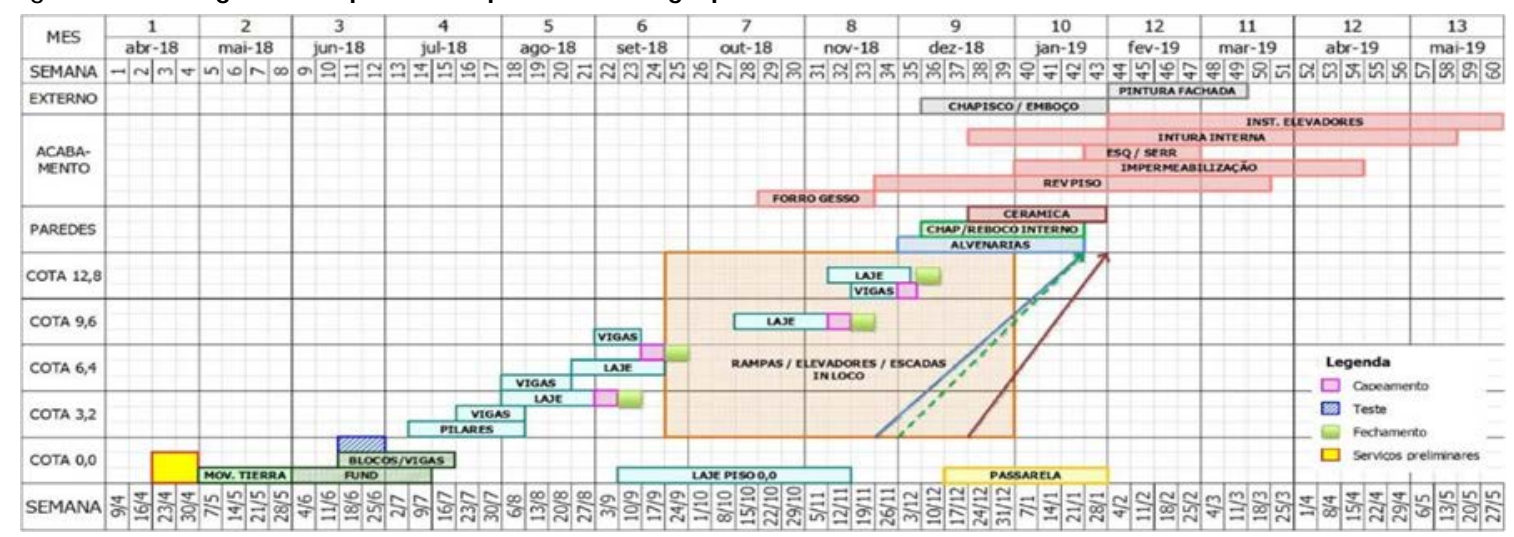


Figura 3 - Planilha de mapeamento de peças por eixo

\begin{tabular}{|c|cccc|}
\hline LOTE & Pilares & Vigas & Lajes & Paineis \\
A & 8 & 32 & 84 & 20 \\
B & 6 & 32 & 112 & 10 \\
C & 8 & 36 & 84 & 15 \\
D & 4 & 16 & 112 & 0 \\
E & 4 & 16 & 112 & 0 \\
UIIII///. & 8 & 36 & 112 & 25 \\
\hline
\end{tabular}

(a) contagem das peças por lote

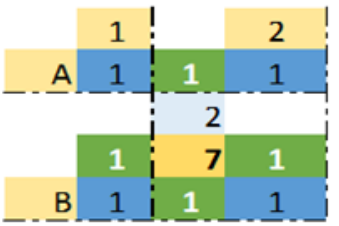

(c) mapeamento espacial do número de peças por eixo

\begin{tabular}{lr}
\hline Painel & 39 \\
\hline Pilar & 105 \\
Vigas & 121 \\
\hline Lajes & 563 \\
\hline Total & 828
\end{tabular}

(d) legenda de peças e quantitativo do projeto arquitetônico

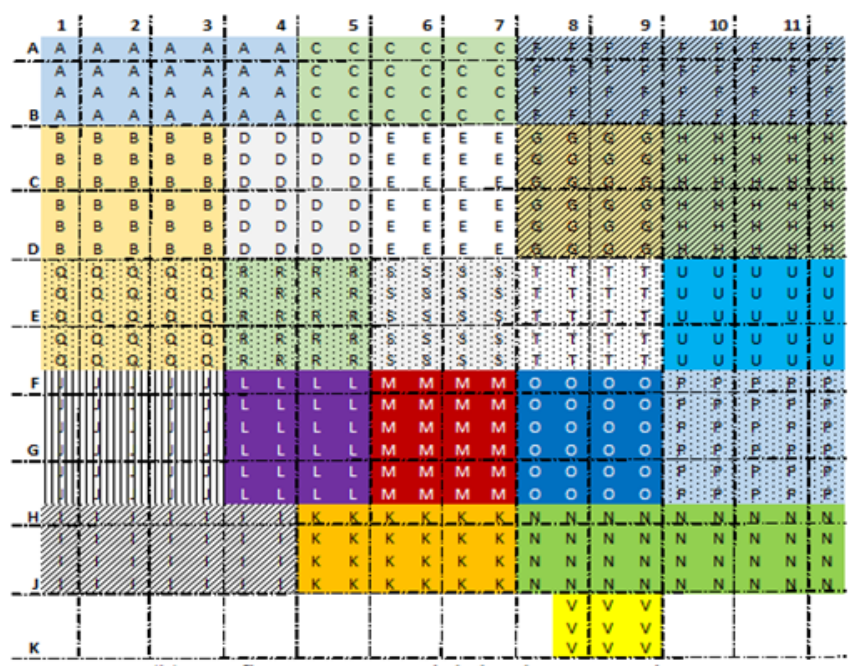

(b) configuração espacial dos lotes por eixos

A Figura 4b mostra a representação esquemática dos lotes em planta baixa, com o número de pilares e a configuração de cada lote. Com a utilização destas duas ferramentas (Figura 3 e Figura 4b), foram simuladas algumas configurações de lotes, sendo que a alternativa com menor tamanho (Figura 4) resultava em 22 lotes. O sequenciamento de montagem é representado na Figura 5. Este sequenciamento representa uma tentativa de execução do mesmo número de peças do conjunto (vigas, lajes e painéis) todos os dias, possibilitando um ciclo de aprendizagem por meio da repetição das peças na mesma quantidade de dias por lote, conforme descrito por Ballard, Harper e Zabelle (2003). É importante salientar que, nesta etapa do estudo, o projeto definia que a laje do pavimento térreo seria moldada in loco. Esta atividade foi representada na linha de balanço (Figura 4a) exatamente como no cronograma inicial. Havia interesse de alterar a solução para peças pré-fabricadas, mas como esta modificação dependia de novo projeto da empresa fornecedora da estrutura préfabricada, não foi considerada nesta etapa do estudo.

\section{Definição do lote pela empresa fornecedora}

O início do processo de montagem da estrutura pré-fabricada atrasou em 18 dias devido à demora na contratação, à realização do detalhamento do projeto estrutural pela fornecedora, e à necessidade de treinamento das equipes de montagem antes do ingresso em obra. Na primeira reunião realizada para apresentar as estratégias de execução já definidas, foi mantida a estimativa de índice de produtividade de montagem, assumindo que este representava $80 \%$ da capacidade produtiva de montagem. A empresa fornecedora, ao elaborar o detalhamento do projeto estrutural, fez algumas modificações de projeto para adequá-lo aos processos de fabricação, entre elas a alteração da execução da laje do térreo para pré-fabricada. Com as alterações realizadas, o número total de peças foi reduzido em $43 \%$ do previsto inicialmente. O número de pilares permaneceu igual, as vigas foram reduzidas em $39 \%$, as lajes reduzidas em $7 \%$, e os painéis aumentaram em 30\%. Em função dessas alterações, a definição dos lotes foi revisada e resultou no cenário 7 com 15 lotes (Figura 6a e Figura 6c). A justificativa para o aumento do tamanho dos lotes no cenário 7 quando comparado ao cenário 6 (Figura 4) não foi plenamente justificada pela empresa fornecedora.

Posteriormente, a empresa fornecedora contratou um consultor de segurança para especificar os equipamentos de proteção coletiva a serem utilizados na obra. A partir da análise do mesmo foi necessário modificar o plano de ataque inicial para o apresentado no cenário 8 (Figura 6b e Figura 6d) - sendo realizado dos eixos A para J. Esta modificação foi necessária de forma a evitar a utilização de equipamentos temporários de proteção contra queda, como bandejas ou andaimes. A solução apresentada pelo consultor foi o isolamento de trechos entre eixos, restringindo o acesso de trabalhadores, e separando os operários da montagem e os operários das outras atividades de acabamento, como o capeamento. O cenário 8 apresentou um número menor de peças por lote em comparação ao cenário 7. 
Figura 4 - LOB do cenário 6

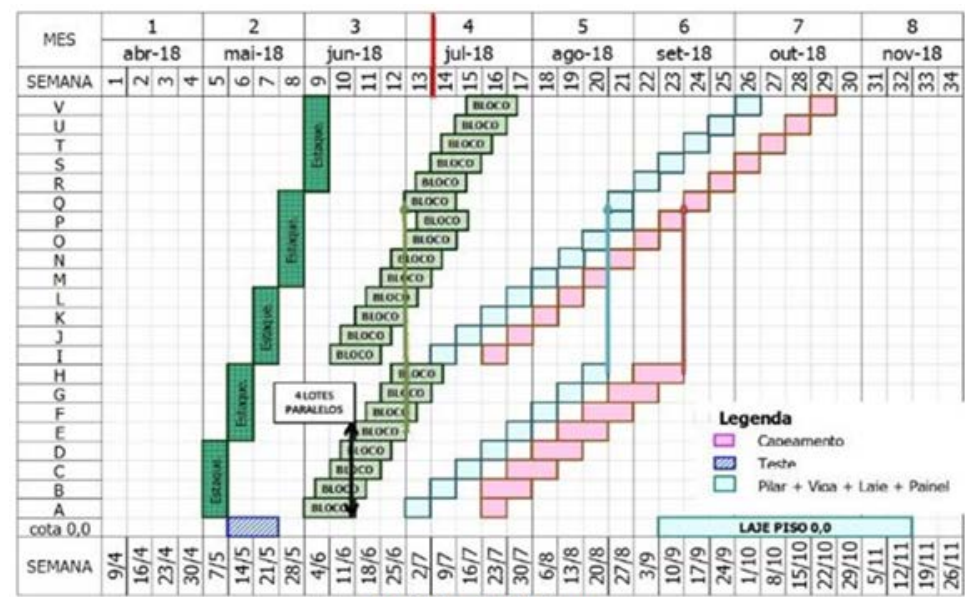

(a) linha de balanço

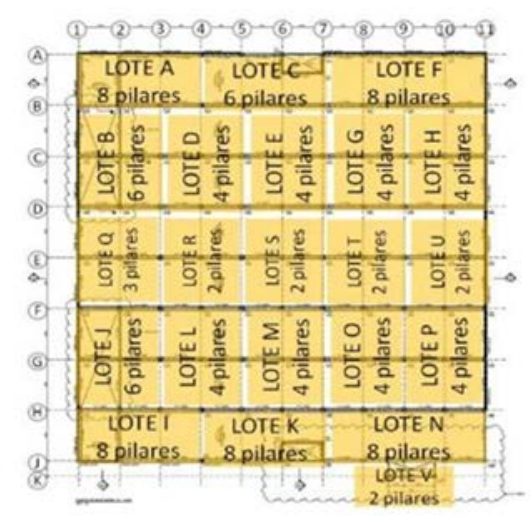

(b) representação esquemática dos lotes

\section{Figura 5 - imagens do modelo 4D apresentando o sequenciamento padronizado do lote}

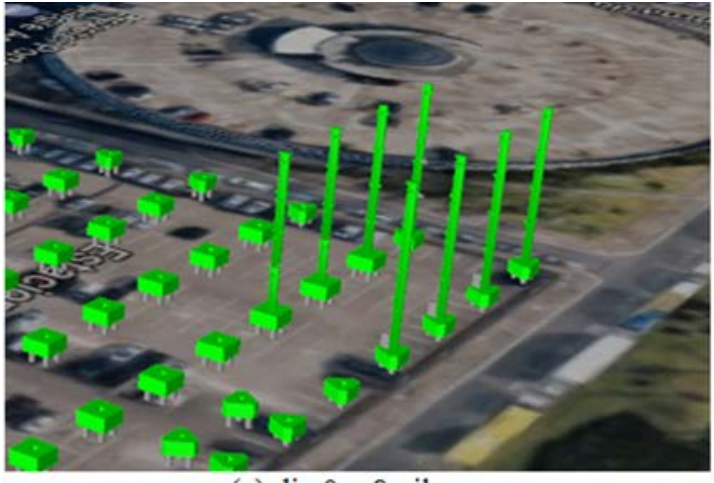

(a) dia $0-8$ pilares

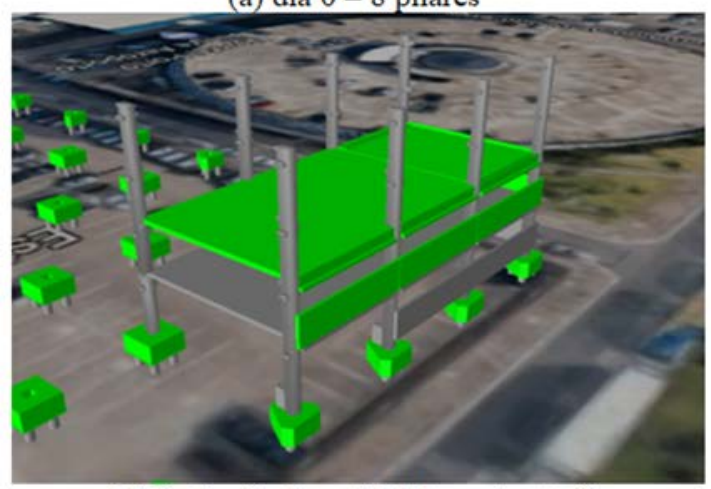

(c) dia $2-8$ vigas, 21 lajes e 4 painéis

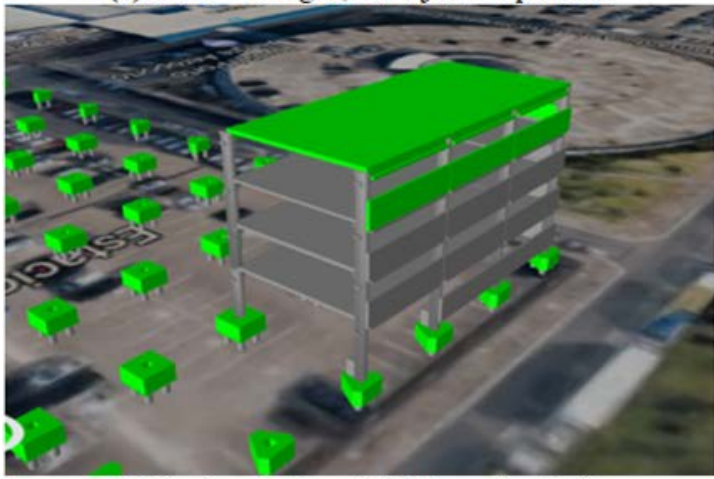

(e) dia $4-8$ vigas, 21 lajes e 4 painéis

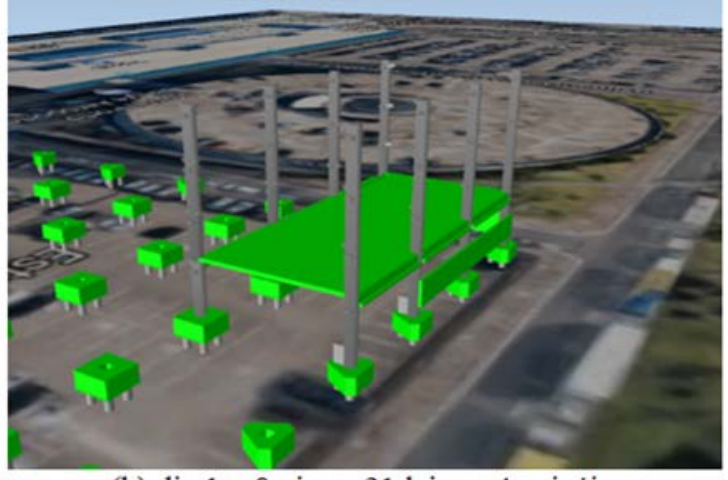

(b) dia $1-8$ vigas, 21 lajes e 4 painéis

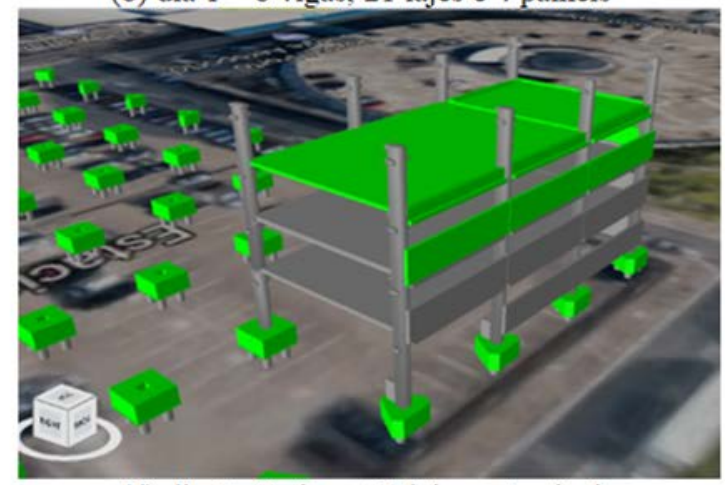

(d) dia 3 - 8 vigas, 21 lajes e 4 paineis

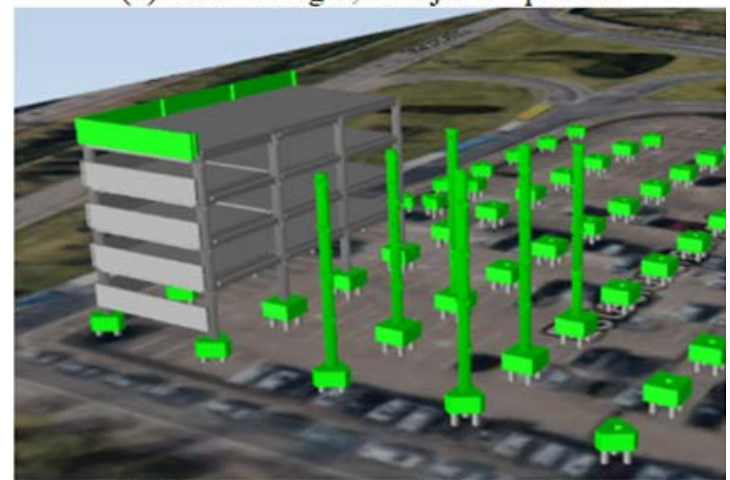

(f) dia $5-8$ vigas, 4 painéis e 6 pilares 
Figura 6 - LOB e definição dos lotes pela empresa fornecedora

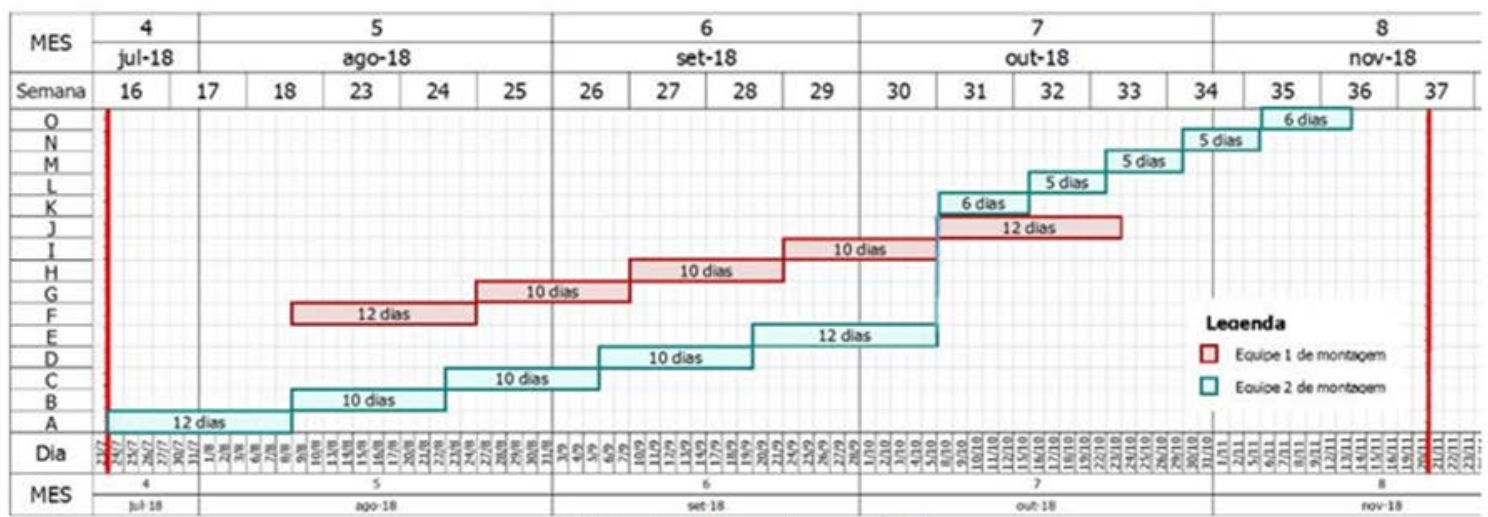

(a) linha de balanço do cenário 7

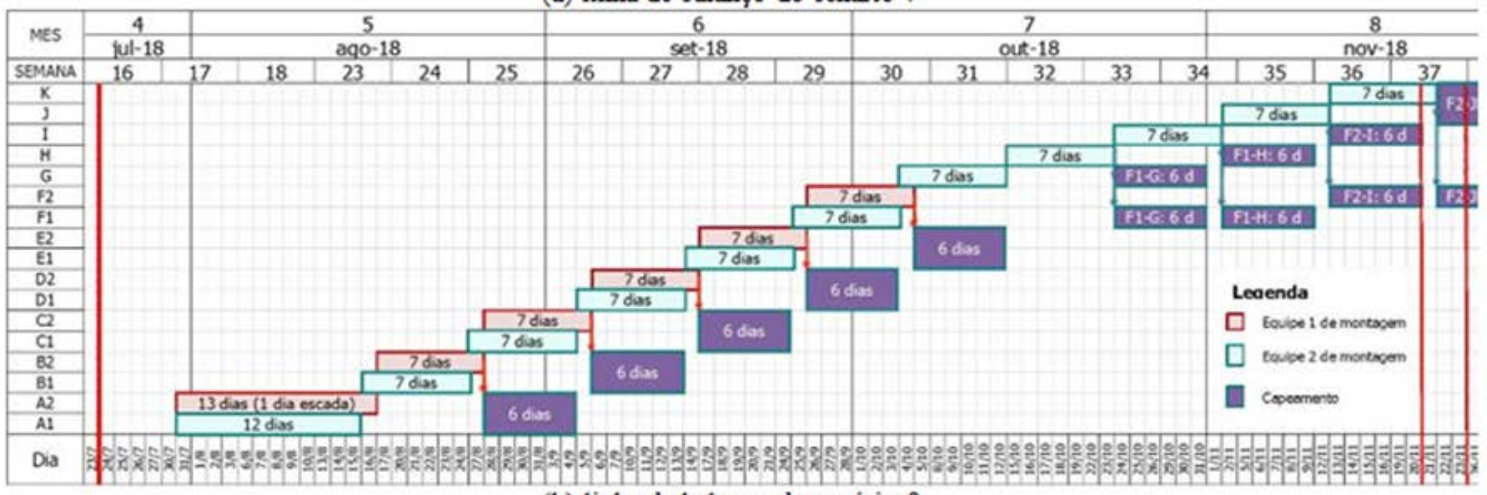

(b) linha de balanço do cenário 8

(1)-(2) - (3)- (4)-(5)-(6) - (7)-(8)-(9) - (10) (11)

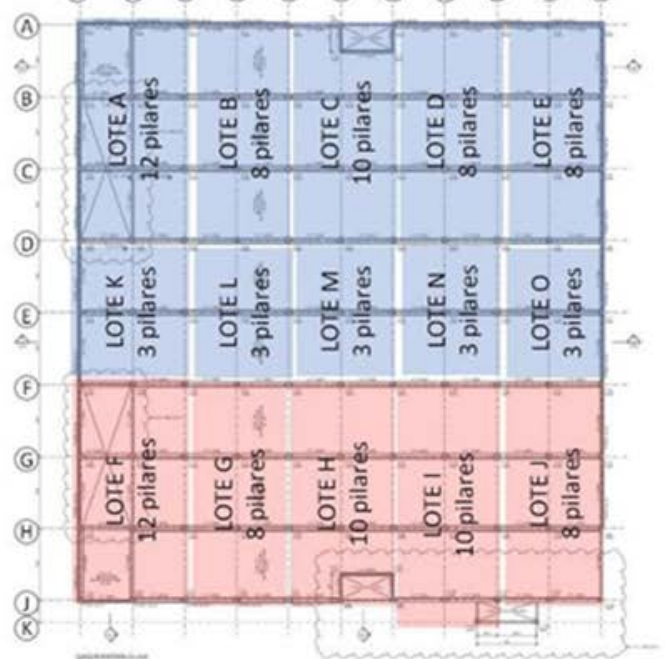

(c) representação esquemática dos lotes cenário 7

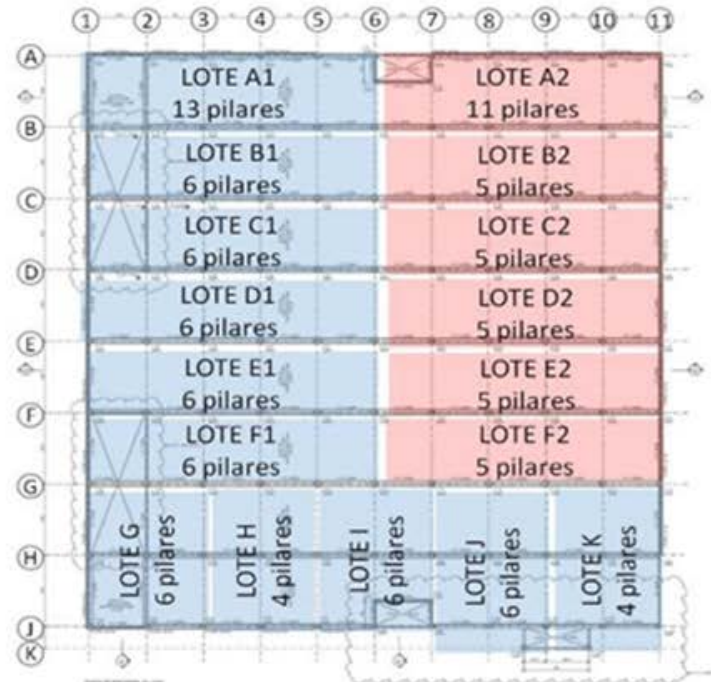

(d) representação esquemática dos lotes cenário 8

\section{Acompanhamento da execução}

Nas etapas iniciais de montagem houve um atraso em relação ao plano estabelecido, o cenário 8. Dessa forma, três outros cenários foram simulados: os cenários 9 e 10 por solicitação das empresas envolvidas, e o cenário 11 proposto pela equipe de pesquisadores.

O cenário 9 (Figura 7a) considerou os dois guindastes trabalhando no turno de trabalho noturno e uma produtividade em torno de $40 \%$ do período diurno. O cenário 10 (Figura $7 \mathrm{~b}$ ) considerou uma terceira frente de trabalho, atuando com a inclusão de um guindaste adicional. Essa solução foi proposta para antecipar a execução dos eixos H-I, que incluíam a montagem das escadas e do poço do elevador, e aumentar o ritmo de produção. 
Como aumentar as frentes de trabalho poderia ocasionar o aumento de trabalho em progresso, foi sugerida a solução do cenário 11 (Figura 7c) pela equipe de pesquisa, modificando o plano de ataque do empreendimento sem aumentar o número de frentes de trabalho. Essa proposta baseou-se também na observação de que havia estoque excessivo de peças em obra (Figura 9), evidenciando a falta de sincronização entre fabricação e montagem, conforme discutido por Čuš-babič et al. (2014).

Os resultados dos três cenários foram discutidos e analisados durante oito reuniões de acompanhamento da produção. Foi também analisado o impacto das operações logísticas com o funcionamento dos três equipamentos ao mesmo tempo. O abastecimento foi planejado para ser realizado diretamente do caminhão para o local de montagem, pelo posicionamento dos caminhões dentro do raio de atuação de cada guindaste (Figura 8). Após as análises, o cenário 10 (Figura 7b) foi escolhido pelos representantes da empresa construtora para recuperar o prazo da obra. A principal justificativa para esta escolha está relacionada a aspectos contratuais: a colocação do terceiro guindaste não representava qualquer custo adicional do ponto de vista da empresa construtora.

\section{Figura 7 - linhas de balanço para os cenários 9 a 11}

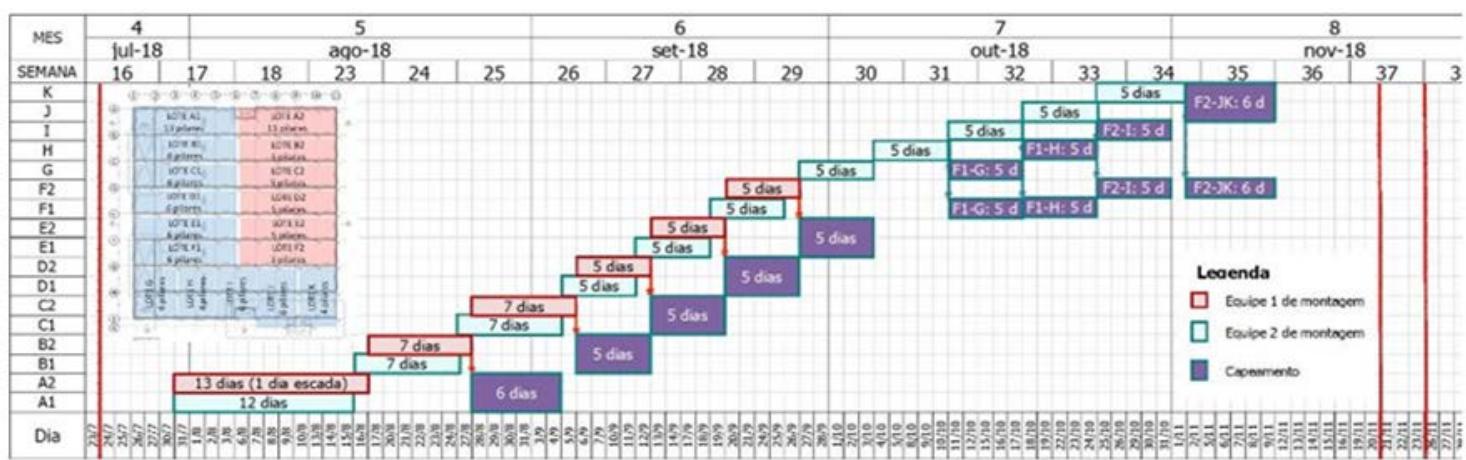

(a) linha de balanço do cenário 9

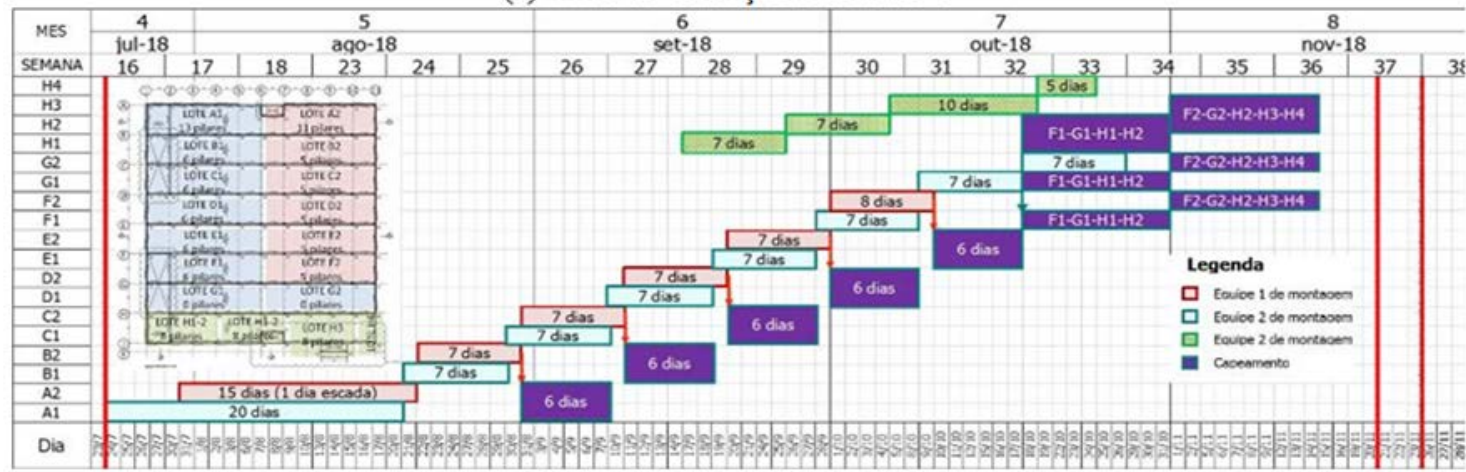

(b) linha de balanço do cenário 10

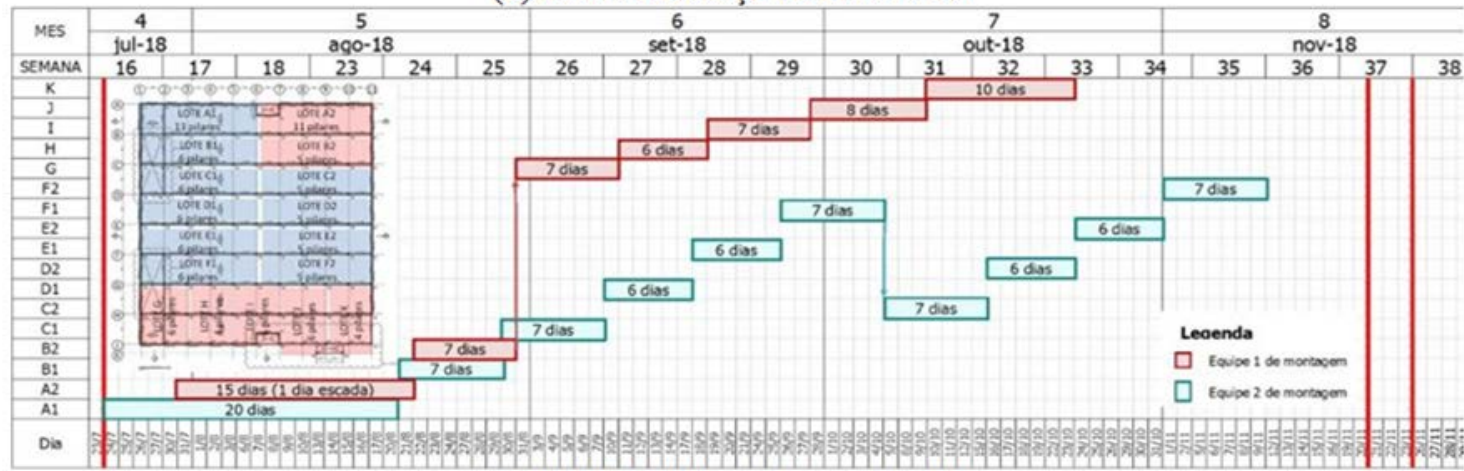

(c) linha de balanço do cenário 11 
Figura 8 - Simulação dos equipamentos em planta baixa

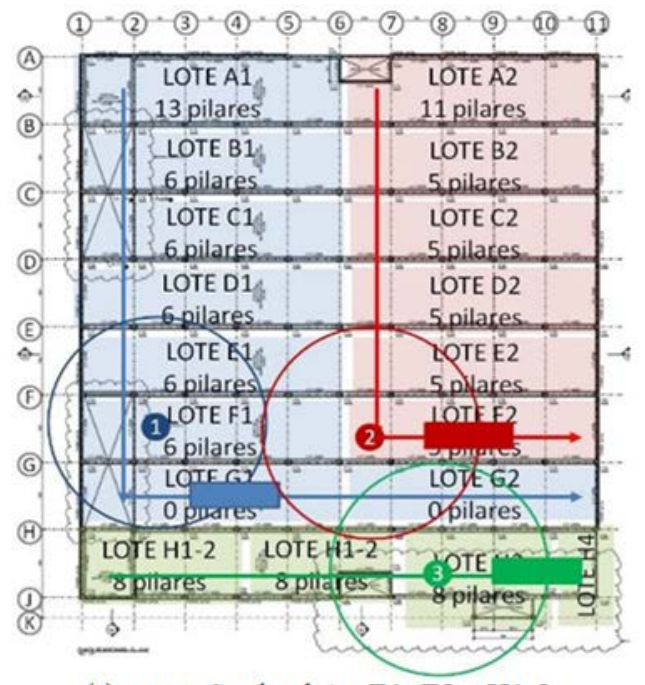

(a) execução dos lotes E1, E2 e H1-2

(1) - (2) - (3) - (4) - (5) - (6) - (7) - (8) - (9) - (19) - (1)

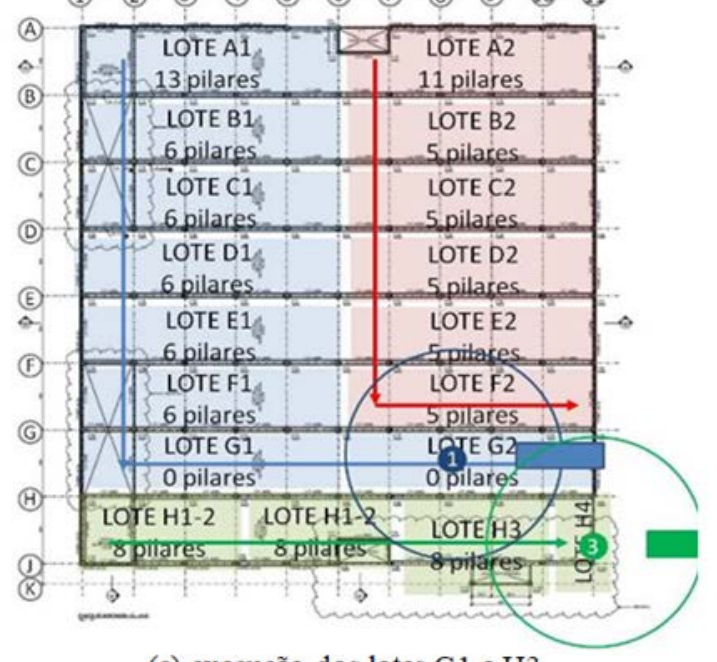

(c) execução dos lotes $\mathrm{G} 1$ e H3

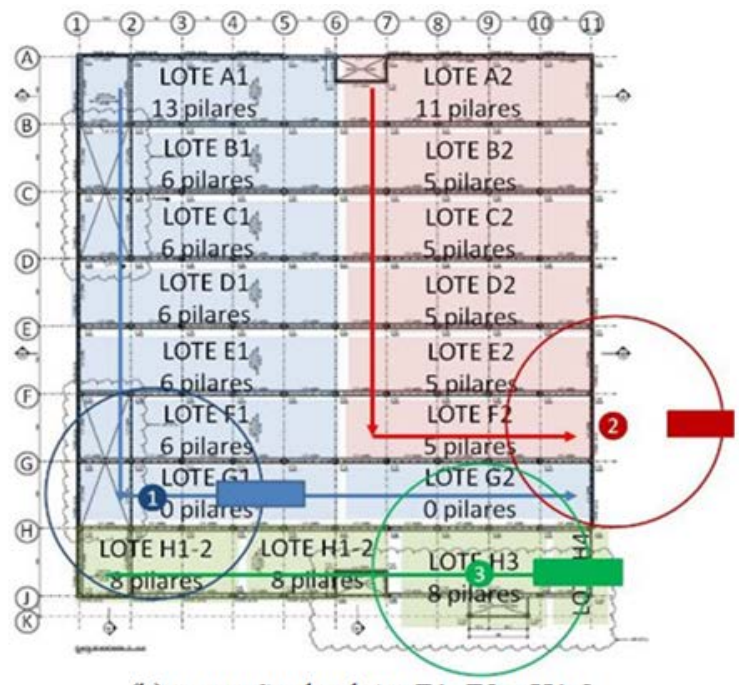

(b) execução dos lotes F1, F2 e H1-2

Figura 9 - Estoque de peças em obra

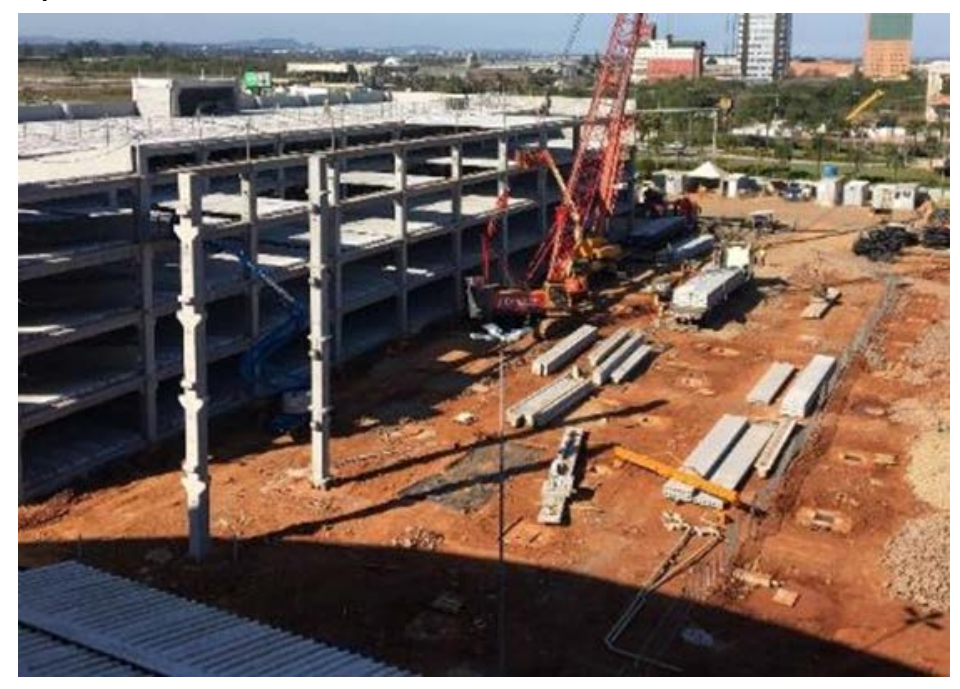


A Figura 10 apresenta o painel visual disposto na sala de reuniões da empresa fornecedora, visando a apoiar o acompanhamento da execução e também as discussões realizadas sobre os diferentes cenários. Foram expostas as seguintes informações: programação por meio de imagens do modelo 4D, gráficos de produtividade, LOB e plano de ataque. Estas informações contribuíram para o monitorar o sequenciamento de execução e a aderência ao lote.

A análise do gráfico de aderência ao lote apontou um aumento no tempo de ciclo dos lotes, causando uma sobreposição na montagem de diferentes lotes e, consequentemente, um aumento no trabalho em progresso (Figura 11a e 11b). A falta de um processo sistemático de identificação e remoção de restrições foi um dos principais motivos para isso, ocasionando transtornos na execução do plano logístico planejado. Duas categorias principais de restrições foram identificadas: indefinições de projeto, e interferências entre equipes de trabalho. A seguir, seguem alguns exemplos de problemas enfrentados:

(a) indefinições no projeto de drenagem pluvial ocasionaram o atraso na conclusão das lajes do térreo no entorno da escada (Figura 12a);

(b) falhas na análise de interdependências entre equipes ocasionaram dificuldade de acesso das carretas e guindastes (Figura 12b) nos eixos planejados, uma vez que houve atraso da execução das redes enterradas de instalações elétricas (Figura 12c);

(c) falhas na remoção de restrições de compactação do solo e definição do projeto de drenagem pluvial no lote $\mathrm{H}$ resultaram no atraso da execução da escada deste lote, sendo modificado o plano de ataque da obra para a execução das rampas nos lotes F1 e G1 (Figura 12d); e

(d) indefinições no projeto de capeamento resultaram no atraso do início da atividade e um aumento do tamanho do lote desta atividade (Figura 12e).

De uma forma geral, observou-se uma tendência a abrir novas frentes de trabalho (ou lotes) sem finalizar as anteriores. Essa falta de terminalidade ocorreu no início da montagem (lotes A1-A2-B1-B2) e após a entrada do terceiro guindaste no canteiro, impactando os lotes D1, D2, E1, E2, F1, F2, G1, G2 e H (lote do terceiro guindaste).

Analisando os dados de produção por tipo de peça por dia (Figura 11c) percebe-se que o número de elementos montados por dia em média (37 peças por dia) foi inferior ao planejado (58 peças por dia). Em relação à inclusão do terceiro guindaste, houve um aumento substancial na produção (de 28 para 46,5 peças por dia), mas o aumento de produtividade foi pequeno, de 14 para 15,5 peças por dia por guindaste, considerando o valor de referência usado no planejamento. Embora a solução adotada tivesse como objetivo cumprir o prazo contratual de entrega da obra, a mesma pode ser criticada por criar um custo adicional pelo aumento do número de equipamentos de montagem, além de aumentar o trabalho em progresso. Outra opção seria entender em mais profundidade as causas reais do atraso da montagem, visando à eliminação das mesmas.

\section{Figura 10 - Painel visual para acompanhamento da execução}

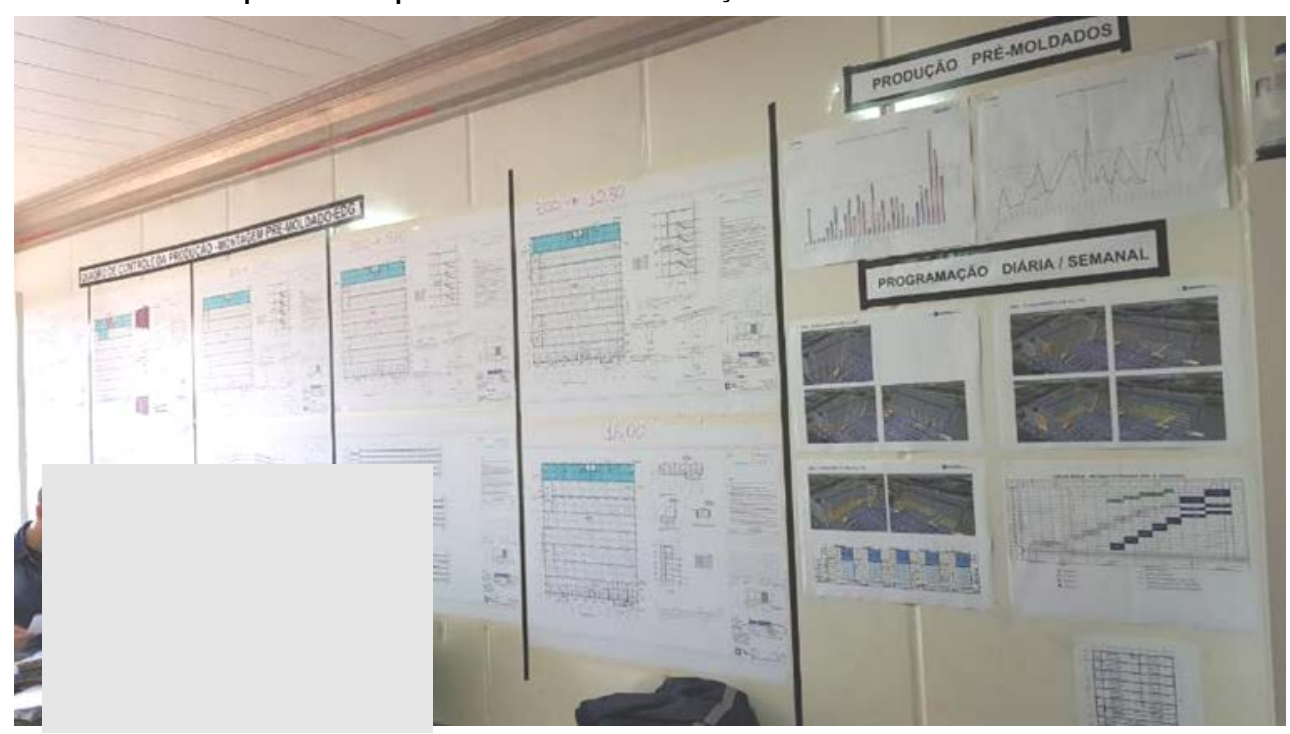




\section{Figura 11 - Gráficos de controle da produção}

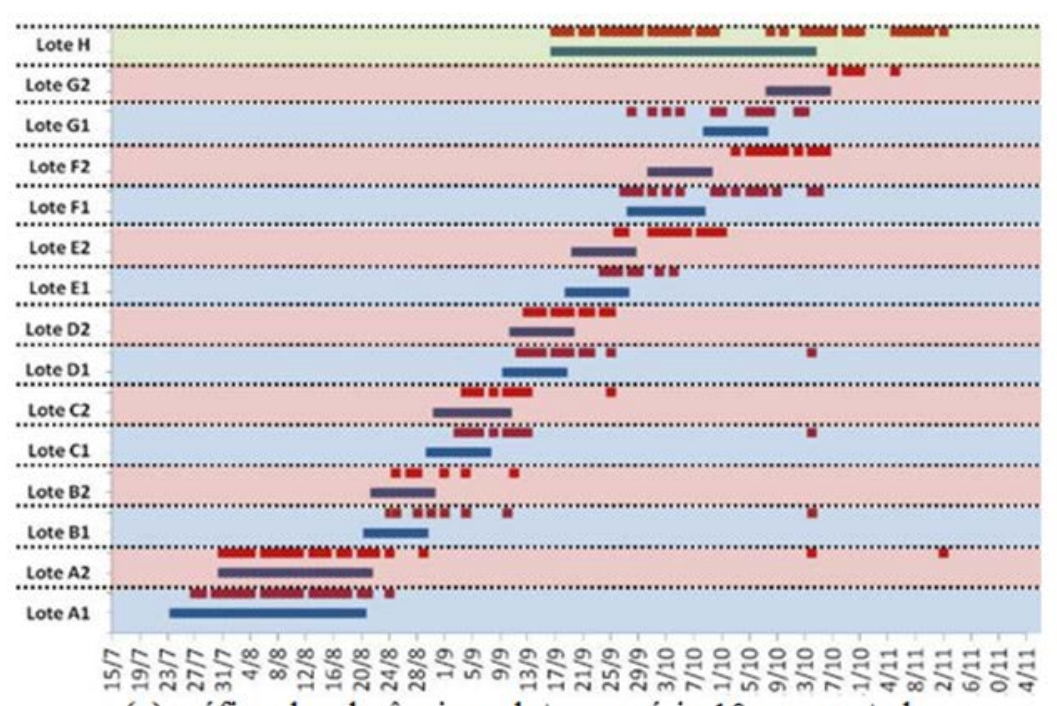

\begin{tabular}{|c|c|c|}
\hline & \multicolumn{2}{|c|}{ Duração (dias) } \\
\hline & Plan. & Exec. \\
\hline H & 28 & 43 \\
\hline G2 & 7 & 8 \\
\hline G1 & 7 & 18 \\
\hline $\mathbf{F} 2$ & 7 & 10 \\
\hline F1 & 7 & 21 \\
\hline E2 & 7 & 12 \\
\hline El & 7 & 9 \\
\hline D2 & 7 & 9 \\
\hline D1 & 7 & 31 \\
\hline C2 & 7 & 16 \\
\hline Cl & 7 & 38 \\
\hline B2 & 7 & 12 \\
\hline B1 & 7 & 44 \\
\hline A2 & 16 & 75 \\
\hline Al & 20 & 21 \\
\hline
\end{tabular}

(b) duração planejada $\mathrm{x}$ executada por lotes

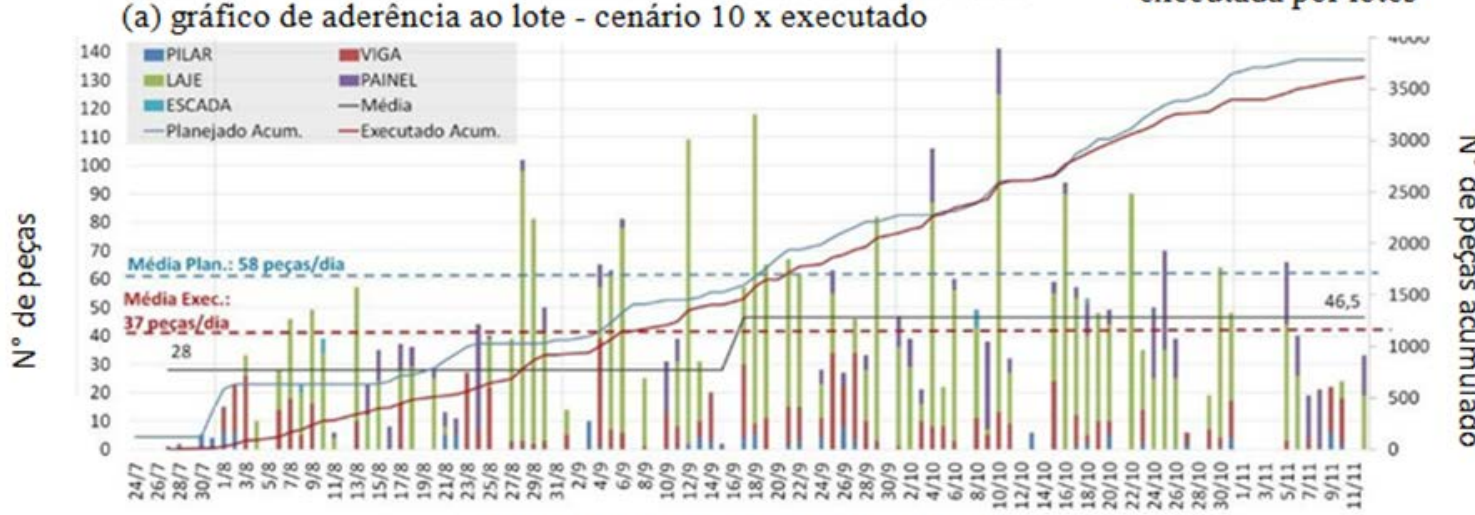

(c) produção por tipo de peça por dia 
Figura 12 - Falhas na remoção de restrições

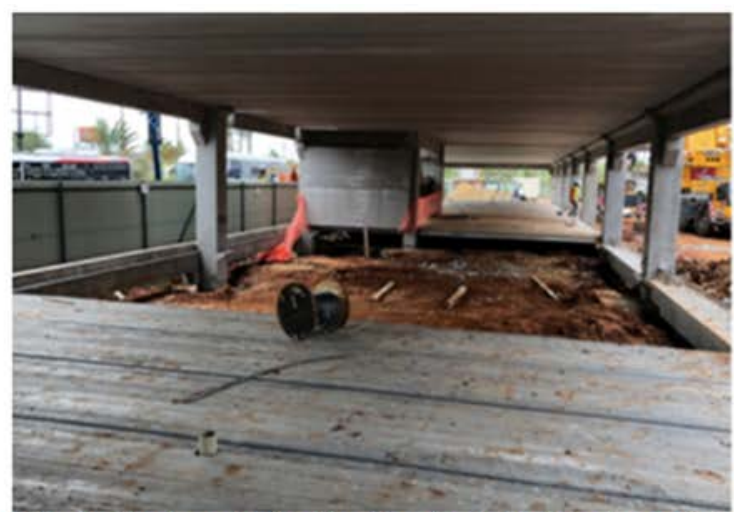

(a) trabalho inacabado devido a indefinição de projeto

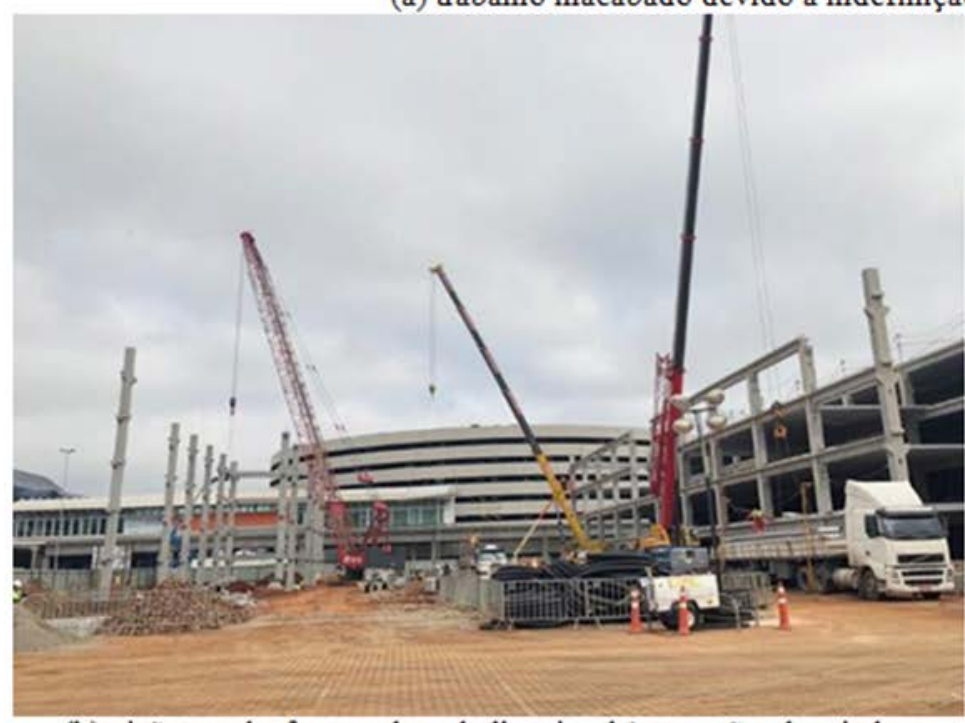

(b) visão geral - frentes de trabalho simultâneas não planejadas

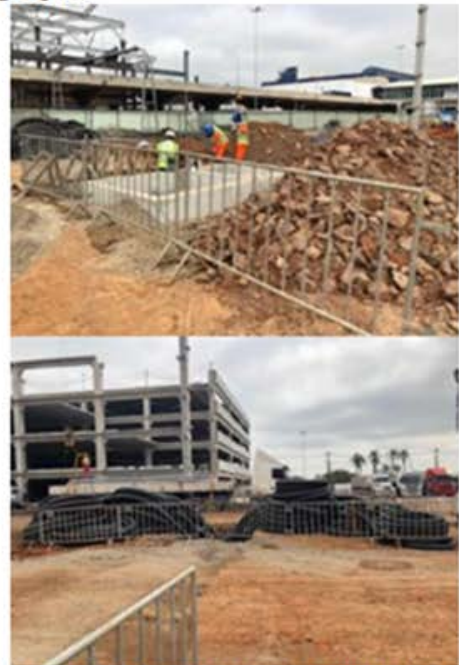

(c) detalhe - frentes de trabalho simultâneas não planejadas

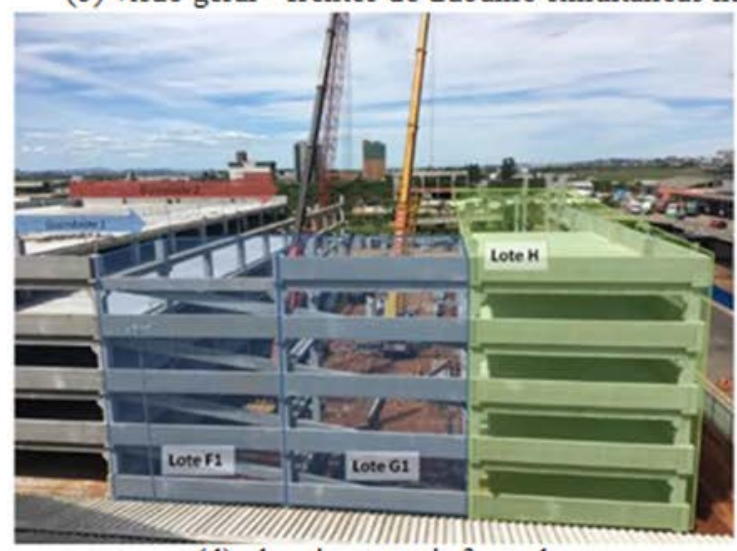

(d) planejamento informal

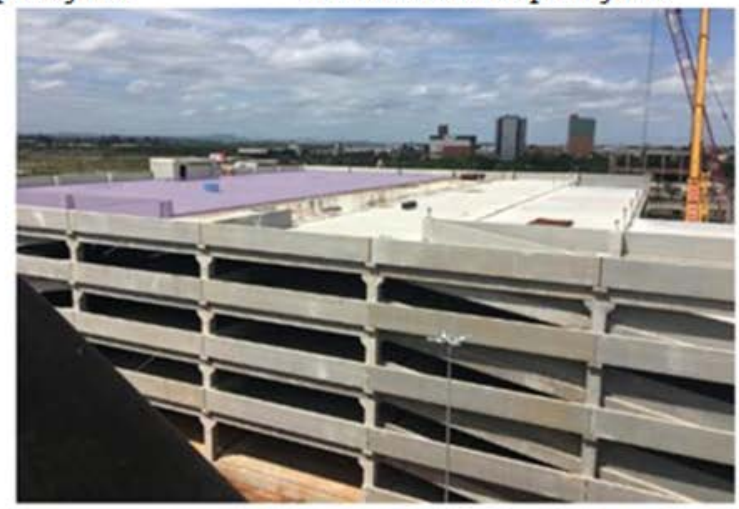

(e) atraso no início do capeamento e aumento do tamanho do lote

\section{Diretrizes para a definição de lotes de montagem de sistemas pré-fabricados de concreto do tipo ETO}

As diretrizes propostas para apoiar a definição dos lotes de produção de sistemas pré-fabricados de concreto foram relacionadas a um conjunto de categorias de decisão interdependentes: o planejamento de leiaute, a definição dos fluxos físicos, e a sincronização da produção. Também foi proposto o uso de ferramentas de planejamento e controle, além do uso da gestão visual como meio para apresentar as informações. Cabe salientar que este escopo é bem mais restrito que o do projeto do sistema de produção, conforme sugerido por 
Schramm e Formoso (2015), já que se referem apenas a decisões envolvidas diretamente na definição dos lotes de produção e algumas interfaces com outras decisões.

As diretrizes são agrupadas em duas unidades de análise (Figura 13): o empreendimento (plano de ataque) e a unidade base ou repetitiva (lote). Para sistemas construtivos ETO, primeiramente deve ser realizada uma análise geral do empreendimento, com estudo dos fluxos de trabalho e definição dos lotes, para posteriormente realizar a análise detalhada desses lotes e definir a sequência de produção. Em relação às etapas de tomada de decisão, pode ser definido um fluxo de decisão para a definição do lote, no qual cada etapa anterior interfere nas decisões da etapa seguinte, e um fluxo de revisão, ou seja, decisões tomadas nas etapas posteriores podem modificar as etapas anteriores, de forma similar ao modelo de Schramm e Formoso (2015). Durante o processo de tomada de decisão, os principais intervenientes no processo de produção e montagem de peças (por exemplo, gerente de produção, representante da empresa fornecedora de pré-fabricados, engenheiro de segurança, entre outros) devem participar das reuniões de discussão dos cenários simulados, de forma a considerar diferentes pontos de vista.

Embora o esforço de definição do lote de montagem parta de um plano de longo prazo, que normalmente é parte de um contrato, existe a necessidade de refinar este plano mediante a criação e discussão de cenários virtuais, que devem obviamente atender a certos elementos contratuais. A Figura 13 representa as etapas de tomada de decisões e as ferramentas utilizadas, que são detalhadas a seguir:

(a) definição dos lotes: para a realização desta etapa devem ser utilizadas a representação esquemática dos lotes em planta baixa (Figura 4b) e planilha de mapeamento de peças (Figura 3). Nesta etapa são definidas ou estimadas a produtividade de montagem e a quantidade de peças por lote. Como resultado temse o número de lotes de montagem e os quantitativos de peças por lote;

(b) estudo dos fluxos de trabalho: para a realização da mesma deve ser utilizada a linha de balanço, na qual é buscada a sincronia entre processos e o fluxo ininterrupto das diferentes equipes. Como resultado desta etapa, tem-se a análise e definição dos fluxos físicos ( ${ }^{\circ}$ de equipes de montagem, sequência de execução dos lotes e sequência de execução das equipes de montagem);

(c) definição de operações logísticas: esta etapa pode ser realizada concomitante à etapa de estudo dos fluxos de trabalho. Podem ser utilizadas representações esquemáticas em planta baixa da localização e movimentação dos equipamentos de montagem, abastecimento e segurança (Figura 8). A explicitação das operações logísticas para a montagem é resultado dessa etapa;

(d) modelagem 4D do empreendimento: esta etapa necessita apenas da definição dos lotes e estudo dos fluxos de trabalho para iniciar, mas só pode ser concluída com a definição das operações logísticas, podendo ser realizada em conjunto com a mesma. Esta etapa apresenta o resultado final do estudo do plano de ataque, reunindo todas as decisões tomadas nas etapas anteriores. Entretanto, a elaboração do modelo 4D traz para o processo de tomada de decisão uma nova compreensão sobre as operações logísticas, por permitir uma visualização das mesmas;

(e) definição da sequência de produção: consiste na elaboração de um diagrama de precedências de atividades de montagem das peças nos lotes. Como resultado se obtém a sequência de atividades a ser seguida na montagem;

(f) definição de ritmo: parte da definição do tempo de ciclo, com base na definição da sequência de produção e da produtividade a ser adotada. Pode ser utilizada uma planilha auxiliar contabilizando a quantidade de peças montadas por dia por lote; e

(g) modelagem 4D do lote: assim como na modelagem 4D do empreendimento, esta etapa reúne informações das etapas anteriores. A elaboração do modelo 4D (Figura 5) traz uma nova compreensão sobre as limitações de montagem, podendo ser necessário modificar decisões das etapas anteriores. 
Figura 13 - Etapas para a definição dos lotes de montagem ETO

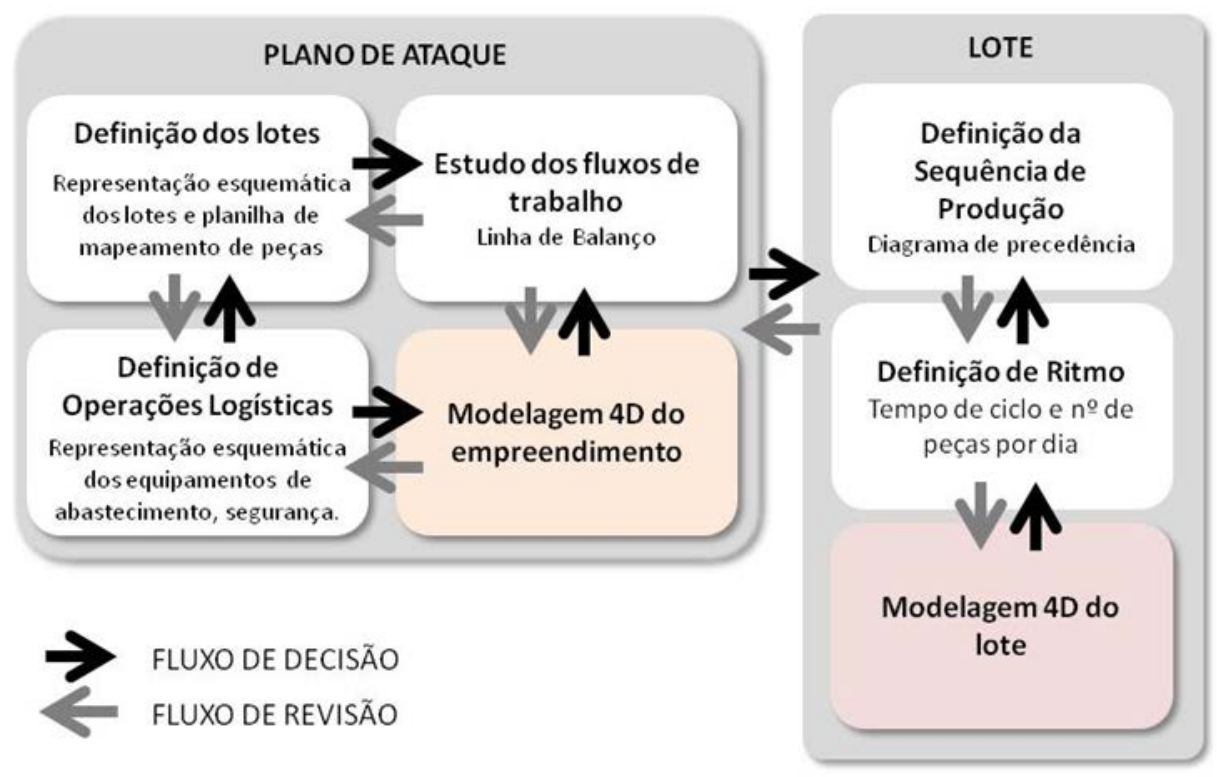

Podem ser feitas algumas conexões entre as diretrizes propostas à aplicação de conceitos e princípios da Lean Production:

(a) redução do tamanho do lote: a representação esquemática dos lotes em planta baixa (Figura 4b) e a planilha de mapeamento de peças (Figura 3) foram utilizadas para reduzir o tamanho do lote e permitir uma certa repetição do empreendimento, visando à padronização de processos, mesmo que esta repetição não seja idêntica em termos de mix de peças. Essa redução do tamanho do lote contribui para a redução do tempo de ciclo e consequentemente permite que as equipes se beneficiem do efeito aprendizagem;

(b) sincronização de operações logísticas e redução das atividades que não agregam valor: tanto a ferramenta de representações esquemáticas em planta baixa da localização e movimentação dos equipamentos de montagem, abastecimento e segurança (Figura 8), como a modelagem 4D das operações logísticas, permitem a eliminação de atividades que não agregam valor;

(c) visualização de fluxos e lotes de produção: a linha de balanço efetivamente complementou a modelagem BIM 4D, conforme sugerido por Biotto, Formoso e Isatto (2015), sendo útil na visualização do fluxo do produto e do trabalho, assim como dos lotes de montagem, facilitando a definição do sequenciamento dos lotes de produção, do ritmo de produção. Com base na sincronização dos processos, pode-se buscar o fluxo ininterrupto das equipes, que é muito importante para a eficiência dos equipamentos de montagem; e

(d) uso da produção puxada como forma de lidar com a variabilidade: o conjunto de ferramentas de controle utilizadas permite que se tenha de forma atualizada o status das atividades acontecendo no canteiro de obras, que é uma informação importante para que a produção da fábrica e a entrega de peças seja puxada pela obra. Por dificuldades de integração com as operações da empresa fornecedora, não foi possível implementar este princípio no estudo realizado.

\section{Avaliação do artefato}

\section{Aplicabilidade}

O Quadro 4 apresenta de forma resumida o tempo de preparação dos modelos 4D. Ao total foram necessárias 100 horas de modelagem para a realização de 11 cenários em 6 meses de estudo. O número de horas entre as fases de definição de lote também diminuiu ao longo do tempo, devido à redução do número de cenários simulados. Assim, houve um efeito aprendizagem na definição de novas variáveis para novos cenários, já que na etapa inicial foram simulados 6 cenários e apenas 2 foram relevantes para análise e discussão. Já na etapa de acompanhamento da execução os 3 cenários simulados foram utilizados para a tomada de decisão. 
A compreensão por parte dos intervenientes das ferramentas e conceitos fundamentais, pode ser evidenciada pela escolha de cenários que apresentaram melhores soluções para lotes de produção. O cenário 6 foi o escolhido pela empresa construtora para apresentação à empresa fornecedora no momento da sua contratação. Este cenário foi elaborado com o menor tamanho de lote do estudo (totalizando 22 lotes - Figura 4) e com repetição de lotes todos os dias (evidenciado no modelo 4D - Figura 5), usando os conceitos de redução do tamanho do lote, redução do tempo de ciclo, efeito aprendizagem e sincronia das operações logísticas. A compreensão da empresa construtora quanto aos conceitos e as ferramentas propostas é evidente ao se comparar os problemas identificados no plano de longo prazo inicial (Figura 2) e o cenário 6. Também é importante salientar que para a empresa construtora a linha de balanço foi utilizada também em outras obras da expansão do aeroporto, sendo disseminada por um engenheiro de planejamento desta empresa, que participou do estudo.

\section{Quadro 4 - Tempo de preparação dos modelos 4D para as reuniões}

\begin{tabular}{|c|c|}
\hline Etapa & $\begin{array}{c}\text { Tempo de preparação dos } \\
\text { modelos 4D }\end{array}$ \\
\hline Definição do lote pela empresa construtora & 56h de modelagem aprox. \\
\hline Definição do lote pela empresa fornecedora & 20h de modelagem aprox. \\
\hline Acompanhamento da execução & 24h de modelagem aprox. \\
\hline Total & 100h de modelagem aprox. \\
\hline
\end{tabular}

Quadro 5 - Complementaridade entre as ferramentas propostas

\begin{tabular}{|c|c|c|}
\hline Ferramenta & Informação apresentada & $\begin{array}{l}\text { Etapas para a } \\
\text { definição dos } \\
\text { lotes de } \\
\text { montagem ETO }\end{array}$ \\
\hline $\begin{array}{l}\text { Representação esquemática } \\
\text { dos lotes em planta baixa }\end{array}$ & Definição dos lotes em planta & $\begin{array}{l}\text { Definição dos } \\
\text { lotes }\end{array}$ \\
\hline $\begin{array}{c}\text { Planilha de mapeamento de } \\
\text { peças }\end{array}$ & Quantificação de peças por lote & $\begin{array}{l}\text { Definição dos } \\
\text { lotes }\end{array}$ \\
\hline Linha de balanço & $\begin{array}{c}\mathrm{N}^{\circ} \text { de equipes de montagem, sequencia de } \\
\text { execução dos lotes e sequencia de } \\
\text { execução das equipes de montagem }\end{array}$ & $\begin{array}{l}\text { Estudo dos fluxos } \\
\text { de trabalho }\end{array}$ \\
\hline $\begin{array}{l}\text { Representações esquemáticas } \\
\text { em planta baixa da localização } \\
\text { e movimentação dos } \\
\text { equipamentos de montagem, } \\
\text { abastecimento e segurança }\end{array}$ & Operações de logística para a montagem & $\begin{array}{l}\text { Definição de } \\
\text { operações } \\
\text { logística }\end{array}$ \\
\hline $\begin{array}{l}\text { Modelo 4D do } \\
\text { empreendimento }\end{array}$ & $\begin{array}{c}\text { Definição dos lotes, quantificação das } \\
\text { peças por lote, } n^{\circ} \text { de equipes de montagem, } \\
\text { sequencia de execução dos lotes e } \\
\text { sequencia de execução das equipes de } \\
\text { montagem e operações de logística para a } \\
\text { montagem } \\
\end{array}$ & $\begin{array}{l}\text { Modelo 4D do } \\
\text { empreendimento }\end{array}$ \\
\hline Diagrama de precedências & $\begin{array}{c}\text { Sequenciamento de montagem de peças e } \\
\text { suas premissas pelos envolvidos no } \\
\text { processo } \\
\end{array}$ & $\begin{array}{l}\text { Definição da } \\
\text { sequência de } \\
\text { produção } \\
\end{array}$ \\
\hline $\begin{array}{c}\text { Planilha auxiliar } \\
\text { contabilizando a quantidade } \\
\text { de peças montadas por dia por } \\
\text { lote }\end{array}$ & $\begin{array}{l}\text { Tempo de ciclo e quantitativo de peças por } \\
\text { dia }\end{array}$ & $\begin{array}{l}\text { Definição de } \\
\text { ritmo }\end{array}$ \\
\hline Modelo 4D do lote & $\begin{array}{l}\text { Sequenciamento das peças no lote, tempo } \\
\text { de ciclo e quantitativo de peças por dia }\end{array}$ & $\begin{array}{l}\text { Modelo 4D do } \\
\text { lote }\end{array}$ \\
\hline
\end{tabular}




\section{Utilidade}

A introdução de um conjunto de conceitos lean no processo de tomada de decisão por meio das diretrizes propostas está explicado ao longo do item de resultados. Quanto à contribuição para a definição de um ciclo de produção curto e com um certo grau de repetição ficou evidenciado pela mudança nos planos de produção no sentido de reduzir o tamanho do lote e tempo de ciclo ao longo do estudo. Foi proposta uma alternativa mais ousada quanto à definição de lotes pela empresa construtora (total de 22 lotes no cenário 6), que não foi possível de ser implementada. Logo a seguir, a empresa fornecedora propôs o cenário 7, com lotes maiores (totalizando 15 lotes). Mas ao final, depois de discussões dos cenários nas reuniões de planejamento de longo prazo da obra, o tamanho dos lotes foi refinado até o cenário 10 (total de 17 lotes).

Quanto à geração de alternativas de planos para apoiar a tomada de decisão, pode ser evidenciado pela simulação dos cenários considerando um turno adicional (cenário 9 - Figura 7a), inclusão do terceiro guindaste (cenário 10 - Figura 7b), além do cenário 11, proposto pelos pesquisadores (Figura 7c). Estes foram sugeridos como alternativas para possíveis atrasos na produção, em etapas iniciais do estudo. Ao longo do acompanhamento da obra, os planos foram refinados e discutidos novamente até a utilização definitiva do cenário 10. Assim, as várias alternativas de cenários de sistema de produção podem ser reutilizadas em momentos mais oportunos.

De acordo com cada etapa de tomada de decisão, uma ferramenta distinta é utilizada para a representação de informações diferentes. Dessa forma, como apresentado no Quadro 5, existe complementaridade entre as ferramentas propostas, permitindo apoiar o processo de tomada de decisão de forma dinâmica e sistemática.

\section{Conclusões}

O presente artigo propôs um conjunto de diretrizes para apoiar a definição dos lotes de montagem para sistemas pré-fabricados de concreto ETO. A definição dessas diretrizes emergiu a partir da análise crítica do processo de definição e controle dos lotes de produção em uma obra aeroportuária.

Como primeira contribuição destaca-se a sistematização das etapas para a definição dos lotes de montagem a partir de duas unidades de análise, o empreendimento e o lote. Percebe-se que a divisão da obra em lotes facilita a etapa de controle de montagem além de oferecer flexibilidade para enfrentar alguns desafios, tais como alterações no projeto e mudanças na sequência de montagem. Para sistemas de produção ETO, as definições de lote são decisões chave para o controle do fluxo de materiais e sincronização entre a fábrica e a obra.

Também se destaca como contribuição a utilização de um conjunto de ferramentas complementares para o processo de tomada de decisão. Estas ferramentas são:

(a) representação esquemática dos lotes em planta baixa;

(b) planilha de mapeamento de peças;

(c) linha de balanço;

(d) representações esquemáticas em planta baixa da localização e movimentação dos equipamentos de montagem, abastecimento e segurança;

(e) modelo 4D do empreendimento;

(f) diagrama de precedências;

(g) planilha para contabilizar a quantidade de peças montadas por dia por lote; e

(h) modelo 4D do lote.

Como contribuição teórica, o presente trabalho aborda os conceitos e princípios da Lean Production que são utilizados na definição do tamanho de lote:

(a) redução do tamanho do lote;

(b) redução do tempo de ciclo;

(c) efeito aprendizagem devido a ciclos mais curtos de produção;

(d) sincronização de operações logísticas e redução das atividades que não agregam valor;

(e) fluxo ininterrupto das diferentes frentes de trabalho; e 
(f) uso da produção puxada como forma de lidar com a variabilidade.

Como limitações do trabalho, pode-se destacar as dificuldades de implementação dos planos propostos, conforme mostrado no gráfico de aderência do lote, em parte pela limitada implementação do planejamento de médio prazo. Salienta-se também a falta de integração entre o processo de montagem e a fabricação de peças pela empresa fornecedora, o que dificultou a implementação do conceito de produção puxada.

Como sugestões para trabalhos futuros podem ser destacados os seguintes:

(a) ampliar o escopo destas diretrizes para o planejamento da expedição e fábrica, criando também uma sistemática de análise definição de lote de fabricação e de expedição para atender a montagem em obra; e

(b) propor a sistematização de controle de montagem a partir dos lotes planejados para retroalimentar de maneira sistemática as definições do plano de longo prazo de montagem.

\section{Referências}

ARDITI, D.; TOKDEMIR, O. B.; SUH, K. Challenges in line-of-balance scheduling. Journal of Construction Engineering and Management, v. 128, n. 6, p. 545-556, 2002.

BALLARD, G.; HARPER, N.; ZABELLE, T. Learning to see work flow: an application of lean concepts to precast concrete fabrication. Engineering, Construction and Architectural Management, v. 10, n. 1, p. 614, 2003.

BATAGLIN, F. S. modelo para gestão dos processos logísticos em obras de sistemas pré-fabricados engineer-to-order. porto Alegre, 2017. Dissertação (Mestrado em Engenharia Civil) - Program de Pósgraduação em Engenharia Civil, Universidade Federal do Rio Grande do Sul, Porto Alegre, 2017.

BATAGLIN, F. S. et al. BIM 4D aplicado à gestão logística: implementação na montagem de sistemas préfabricados de concreto engineer-to-order. Ambiente Construído, Porto Alegre, v. 18, n. 1, p. 171-190, jan./mar. 2018.

BERTRAND, J. W. M.; MUNTSLAG, D. R. Production control in engineer-to-order firms. International Journal of Production Economics, v. 30-31, p. 3-22, 1993.

BIOTTO, C. N.; FORMOSO, C. T.; ISATTO, E. L. Uso de modelagem 4D e Building Information Modeling na gestão de sistemas de produção em empreendimentos de construção. Ambiente Construído, Porto Alegre, v. 15, n. 2, p. 79-96, abr./jun. 2015.

BORTOLINI, R.; FORMOSO, C. T.; VIANA, D. D. Site logistics planning and control for engineer-toorder prefabricated building systems using BIM 4D modeling. Automation in Construction, v. 98, n. 2019, p. 248-264, 2019.

BULHÕES, I. Diretrizes para implementação de fluxo continuo na construção civil : uma abordagem baseada na mentalidade enxuta. Campinas, 2009. Tese (Doutorado em Engenharia Civil) - Program de Pósgraduação em Engenharia Civil, Universidade Estadual de Campinas, Campinas, 2009.

BULHÕES, I. R.; PICCHI, F. A.; FOLCH, A. T. Actions to implement continuous flow in the assembly of pre-fabricated concrete structure. In: ANNUAL CONFERENCE OF THE INTERNATIONAL GROUP FOR LEAN CONSTRUCTION, 14., Santiago, 2006. Proceedings [...] Santiago, 2006.

CHAVADA, R.; DAWOOD, N.; KASSEM, M. Construction workspace management : the development and application of a novel nD planning approach and tool. Journal of Information in Construction, v. 17, p. 213-236, 2012.

CHOI, B. et al. Framework for work-space planning using four-dimensional bim in construction projects. Journal of Construction Engineering and Management, v. 140, n. 9, p. 04014041, 2014.

ČUŠ-BABIČ, N. et al. Supply-chain transparency within industrialized construction projects. Computers in Industry, v. 65, n. 2, p. 345-353, 2014.

EASTMAN, C. et al. BIM handbook: a guide to building information modeling for owners, managers, designers, engineers, and contractors. New York: John Wiley \& Sons, 2011.

FARD, M. G. et al. Visualization of construction progress monitoring with 4D Simulation model overlaid on time-lapsed photographs. Journal of Computing in Civil Engineering, v. 23, n. 6, p. 391-404, 2009. 
GLEDSON, B. J.; GREENWOOD, D. The adoption of 4D BIM in the UK construction industry: an innovation diffusion approach. Journal of Engineering, Construction and Architectural Management, v. 24, n. 6, p. 950-967, 2017

GOSLING, J.; NAIM, M. M. Engineer-to-order supply chain management: a literature review and research agenda. International Journal of Production Economics, v. 122, n. 2, p. 741-754, 2009.

HOPP, W. J.; SPEARMAN, M. L. To pull or not to pull: what is the question? Manufacturing \& Service Operations Management, v. 6, n. 2, p. 133-148, 2004.

JÄRVINEN, P. Action research is similar to design science. Quality and Quantity, v. 41, n. 1, p. 37-54, 2007.

JONGELING, R.; OLOFSSON, T. A Method for planning of work-flow by combined use of location-based scheduling and 4D CAD. Automation in Construction, v. 16, n. 2, p. 189-198, 2007.

KANKAINEN, J.; SEPPÄNEN, O. A line-of-balance based schedule planning and control system. In: ANNUAL CONFERENCE OF THE INTERNATIONAL GROUP FOR LEAN CONSTRUCTION, 11. Virginia, 2003. Proceedings [...] Virginia, 2003.

KASSEM, M.; DAWOOD, N.; CHAVADA, R. Construction workspace management within an industry foundation class-compliant 4D tool. Automation in Construction, v. 52, p. 42-58, abr. 2015.

KOSKELA, L. Application of the new philosophy to construction. Stanford: Stanford University, 1992.

LEE, S.; YU, J.; JEONG, D. BIM acceptance model in construction organizations. Journal of Management in Engineering, v. 31, n. 1988, p. 04014048, 2013.

LESSING, J.; STEHN, L.; EKHOLM, A. Industrialised housing: definition and categorization of the concept. In: INTERNATIONAL GROUP FOR LEAN CONSTRUCTION CONFERENCE, 13., Sydney, 2005. Proceedings [...] Sydney, 2005.

LOWE, R. H. et al. A Comparison of location-based scheduling with the traditional critical path method. In: ANNUAL MEETING AMERICAN COLLEGE OF CONSTRUCTION LAWYERS, San Francisco, 2012. Proceedings [...] San Francisco, 2012.

LUKKA, K. The constructive research approach. Case Study Research in Logistics, v. Series B, p. 83-101, 2003.

MCGOVERN, T.; HICKS, C.; EARL, C. F. Modelling supply chain management processes in engineer-toorder companies. International Journal of Logistics Research and Applications: A Leading Journal of Supply Chain Management, v. 2, n. 2, p. 147-159, 1999.

MELLO, M. H.; STRANDHAGEN, J. O.; ALFNES, E. Analyzing the factors affecting coordination in engineer-to-order supply chain. International Journal of Operations and Production Management, v. 35, n. 7, p. 1005-1031, 2015.

PAPADONIKOLAKI, E.; VRIJHOEF, R.; WAMELINK, H. Supply chain integration with BIM: a graphbased model. Structural Survey, v. 33, n. 3, p. 257-277, 2015.

PHENG, L. S.; CHUAN, C. J. Just-in-time management of precast concrete components. Journal of Construction Engineering and Management, p. 494-501, dec. 2001.

RAUCH, E.; DALLASEGA, P.; MATT, D. T. Complexity reduction in engineer-to-order industry through real-time capable production planning and control. Production Engineering, v. 12, n. 3-4, p. 341-352, 2018.

SACKS, R. et al. Interaction of lean and building information modeling in construction. Journal of Construction Engineering and Management, v. 136, n. 9, p. 968-980, 2010.

SACKS, R.; RADOSAVLJEVIC, M.; BARAK, R. Requirements for building information modeling based lean production management systems for construction. Automation in Construction, v. 19, n. 5, p. 641655, 2010.

SAID, H.; EL-RAYES, K. Optimal material logistics planning in congested construction sites. In: CONSTRUCTION RESEARCH CONGRESS, West Lafayette, 2012. Proceedings [...] West Lafayette, 2012.

SCHLUETER, A.; THESSELING, F. Building Information model based energy/exergy performance 
assessment in early design stages. Automation in Construction, v. 18, n. 2, p. 153-163, 2009.

SCHRAMM, F. K.; FORMOSO, C. T. Projeto de sistemas de produção na construção civil empregando simulação no apoio à tomada de decisão. Ambiente Construído, Porto Alegre, v. 15, n. 4, p. 165-182, 2015.

SKJELBRED, S.; FOSSHEIM, M. E.; DREVLAND, F. Comparing different approaches to site organization and logistics: multiple case studies. In: ANNUAL CONFERENCE OF THE INTERNATIONAL GROUP FOR LEAN CONSTRUCTION, 23., San Francisco, 2015. Proceedings [...] San Francisco, 2015.

THOMAS, H. R. et al. Reducing variability to improve performance as a lean construction principle. Journal of Construction Engineering and Management, v. 128, n. 2, p. 144-154, 2002.

VAN AKEN, J. E. Management research based on the paradigm of the design sciences: the quest for fieldtested and grounded technological rules. Journal of Management Studies, v. 41, n. 2, p. 219-246, 2004.

VIANA, D. D. Integrated production planning and control model for engineer-to-order prefabricated building systems. Porto Alegre, 2015. Tese (Doutorado em Engenharia Civil) - Programa de Pós-graduação em Engenharia Civil, Universidade Federal do Rio Grande do Sul, Porto Alegre, 2015.

YU, Q.; LI, K.; LUO, H. A BIM-based dynamic model for site material supply. Procedia Engineering, v. 164, p. 526-533, jun. 2016.

ZHANG, C. et al. Quantitative assessment of building constructability using BIM and 4D simulation. Open Journal of Civil Engineering, v. 6, n. 3, p. 442-461, 2016.

ZHANG, J.; LI, D. Research on 4D virtual construction and dynamic management system based on BIM. In: INTERNATIONAL CONFERENCE ON COMPUTING IN CIVIL AND BUILDING ENGINEERING, 13. Nottingham, 2010. Proceedings [...] Nottingham, 2010.

\section{Raquel Hoffmann Reck}

Programa de Pós-graduação em Engenharia Civil: Construção e Infraestrutura | Universidade Federal do Rio Grande do Sul | Av. Osvaldo Aranha, 99, 70 andar, sala 706 | Porto Alegre - RS - Brasil | CEP 90035-190 | Tel.: (51) 3308-4848 | E-Mail: raquel.reck@ufrgs.br

\section{Fernanda Saidelles Bataglin}

Programa de Pós-graduação em Engenharia Civil: Construção e Infraestrutura | Universidade Federal do Rio Grande do Sul | E-mail: fernanda.saidelles@ufrgs.br

\section{Carlos Torres Formoso}

Programa de Pós-graduação em Engenharia Civil: Construção e Infraestrutura | Universidade Federal do Rio Grande do Sul | E-mail: formoso@ufrgs.br

\section{Karina Bertotto Barth}

Programa de Pós-graduação em Engenharia Civil: Construção e Infraestrutura | Universidade Federal do Rio Grande do Sul | E-mail: kbertotto@gmail.com

Thomas Diepenbruck

Superintendente Técnico | HTB Engenharia e Construção S. A. | Av. Alfredo Egídio de Souza Aranha, 145, Santo Amaro | São Paulo - SP Brasil | CEP 04726-170 | Tel.: (11) 5643-0100 | E-mail: thomas.diepenbruck@htb.eng.br

\section{Eduardo Luis Isatto}

Programa de Pós-graduação em Engenharia Civil: Construção e Infraestrutura | Universidade Federal do Rio Grande do Sul | E-mail: isatto@ufrgs.br

\section{Ambiente Construído}

Revista da Associação Nacional de Tecnologia do Ambiente Construído

Av. Osvaldo Aranha, 99 - 3o andar, Centro

Porto Alegre - RS - Brasil

CEP $90035-190$

Telefone: +55 (51) 3308-4084

Fax: +55 (51) 3308-4054

www. seer. ufrgs. br/ ambienteconstruido

E-mail: ambienteconstruido@ufrgs.br 
